\title{
Design, Construction, and Analysis of a Pilot-Scale Automated Drilling Platform
}

Cody Smith

Follow this and additional works at: https://researchrepository.wvu.edu/etd

\section{Recommended Citation}

Smith, Cody, "Design, Construction, and Analysis of a Pilot-Scale Automated Drilling Platform" (2017). Graduate Theses, Dissertations, and Problem Reports. 6676.

https://researchrepository.wvu.edu/etd/6676

This Thesis is protected by copyright and/or related rights. It has been brought to you by the The Research Repository @ WVU with permission from the rights-holder(s). You are free to use this Thesis in any way that is permitted by the copyright and related rights legislation that applies to your use. For other uses you must obtain permission from the rights-holder(s) directly, unless additional rights are indicated by a Creative Commons license in the record and/ or on the work itself. This Thesis has been accepted for inclusion in WVU Graduate Theses, Dissertations, and Problem Reports collection by an authorized administrator of The Research Repository @ WVU. For more information, please contact researchrepository@mail.wvu.edu. 


\title{
Design, Construction, and Analysis of a Pilot- Scale Automated Drilling Platform
}

\author{
Cody Smith \\ Thesis Submitted to the \\ Benjamin M. Statler College of Engineering and Mineral Resources \\ at West Virginia University
}

in partial fulfillment of the requirements for the degree of Master of Science in Petroleum and Natural Gas Engineering

Ilkin Bilgesu, Ph. D., Chair Samuel Ameri, M.S. Mark Sindelar, Ph. D. Department of Petroleum and Natural Gas Engineering

Morgantown, West Virginia 2017

Keywords: Drilling Automation, Drill Rig Construction Copyright 2017, Cody Smith 


\section{ABSTRACT \\ Design, Construction, and Analysis of a Pilot-Scale Automated Drilling Platform \\ Cody Smith}

This project and the associated research investigates automation techniques for drilling operations, along with the analysis involved in building an automated pilotscale drilling platform. The outcome from this research investigates feasible technologies and techniques that can be used to automate a pilot-scale drilling rig, with the intent that these practices may provide insight into the construction or procedures of full scale rigs. Both the theory and lab exercise components of this research were completed in association with the Drillbotics competition sponsored by the Drilling Systems Automation Technical Section (DSATS) committee of the Society of Petroleum Engineers (SPE). This study includes all calculations and research conducted during Phase 1 of the competition, which included the design and justification of a lab-scale drilling rig, as well as the construction and testing of the rig during Phase 2.

As drilling automation continues to expand within the industry, testing new technologies in a reliable and transferable manner will be extremely important to the development of a fully automated drilling platform. The intention of this research is focused less on the structural analysis of industry drilling rigs, which has been conducted numerous times in detail, and more on design and construction process for inexpensive, lab-scale rigs that companies could use to assess new automation techniques and technologies. The rig that was designed and tested for the 2015-2016 Drillbotics competition was a success, allowing the West Virginia University team to test four different drilling bits and eight different rock types, and also winning the competition by drilling the provided rock sample with the highest Rate of Penetration (ROP). As such, the Drillbotics competition served as a platform to allow this research to demonstrate the process involved in constructing a fully automated drilling rig. 


\section{TABLE OF CONTENTS}

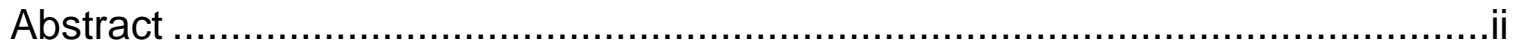

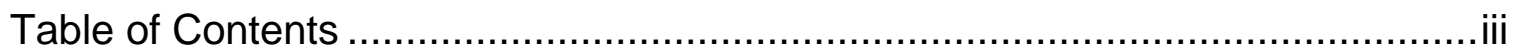

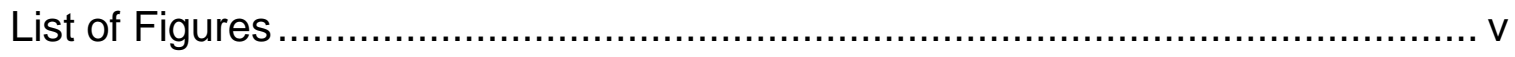

List of Tables ..........................................................................................

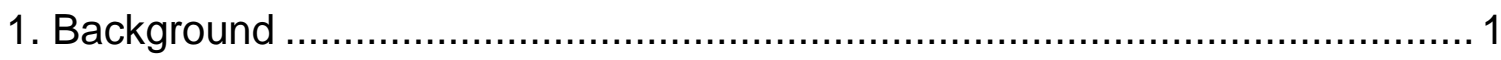

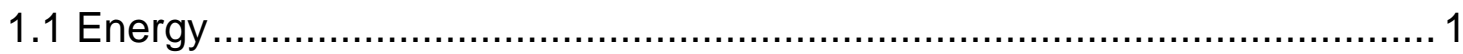

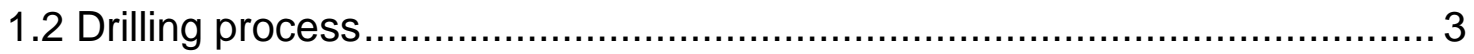

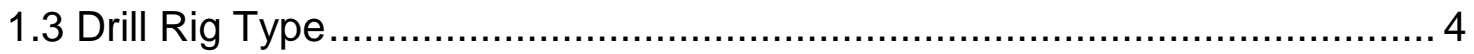

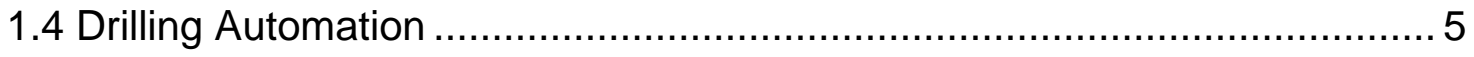

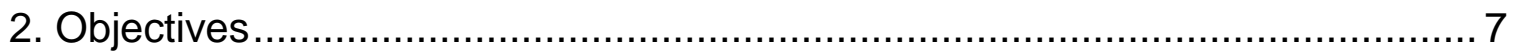

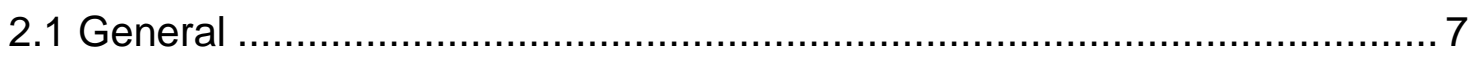

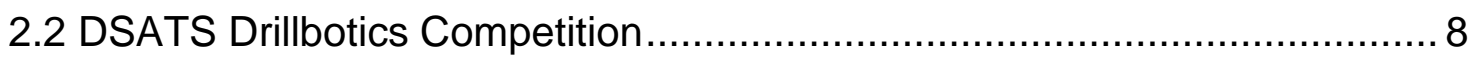

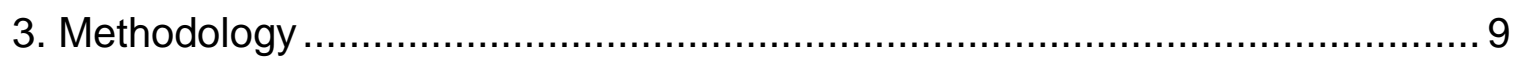

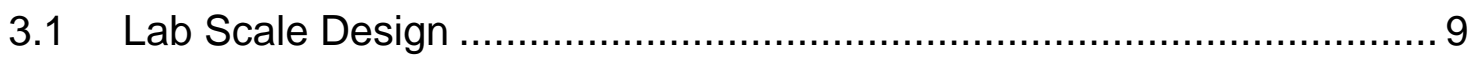

3.2 Budget and Considerations ............................................................... 10

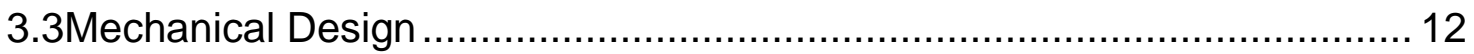

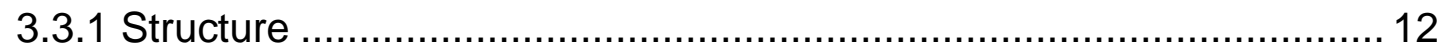

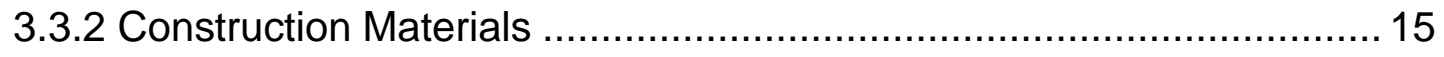

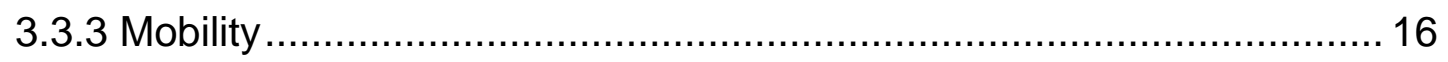

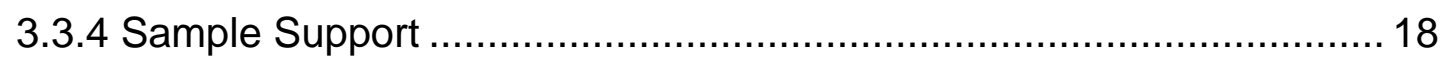

3.3.5 Torque and Combined Loading.................................................... 21

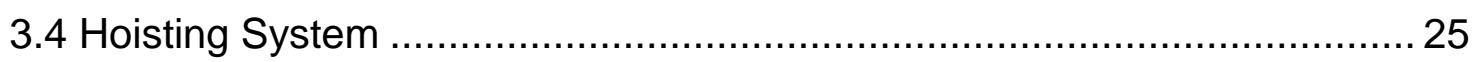

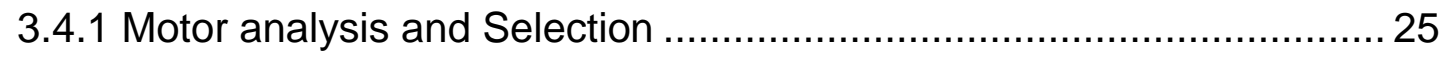

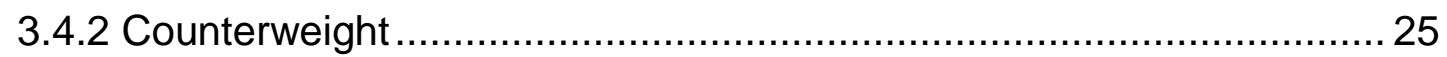




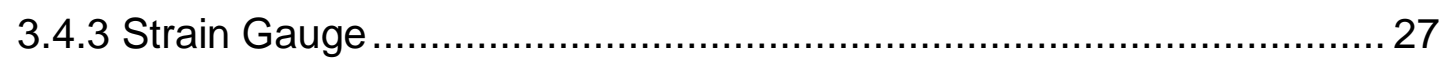

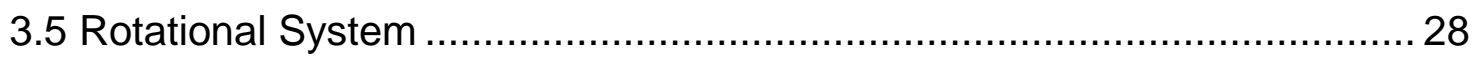

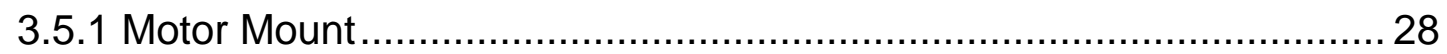

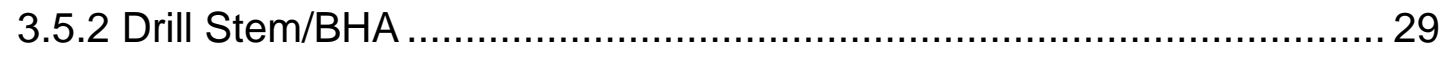

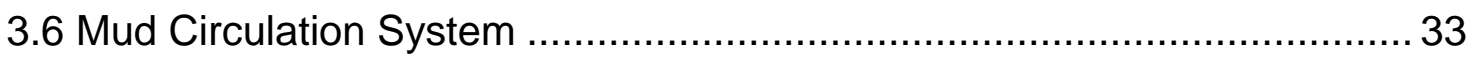

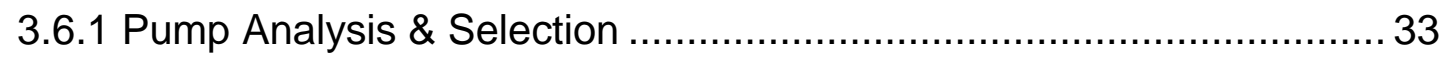

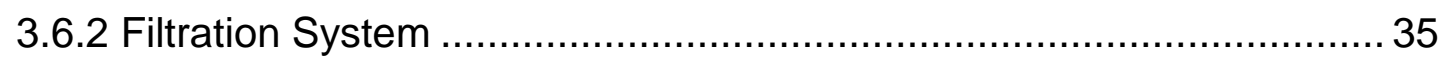

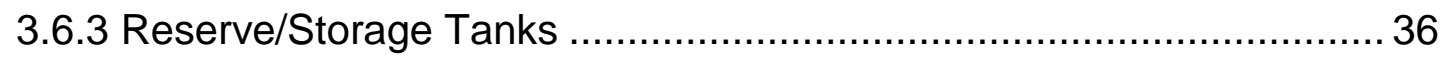

3.6.4 Bell Nipple and Conductor Casing ................................................ 37

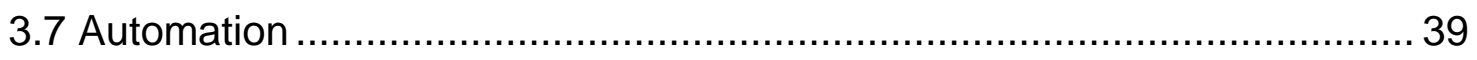

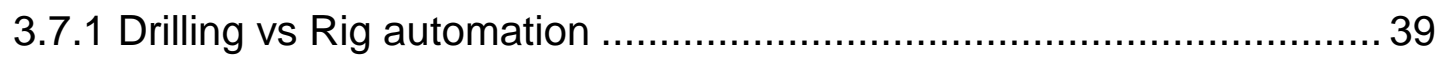

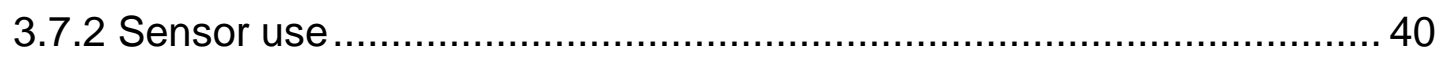

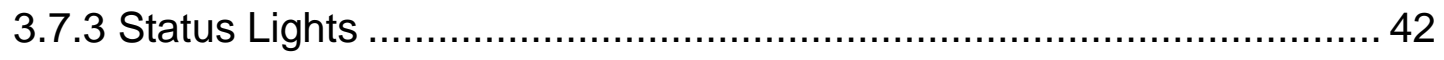

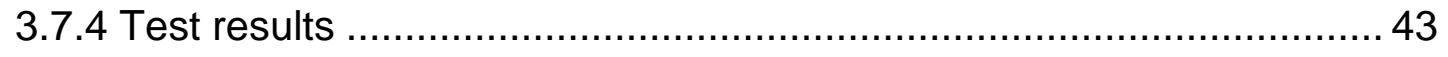

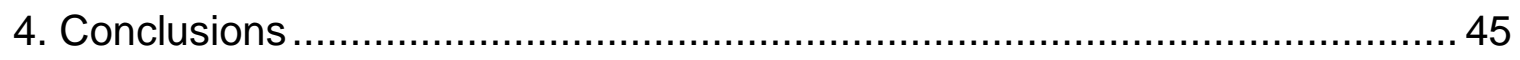

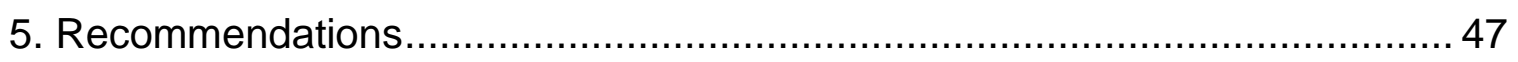

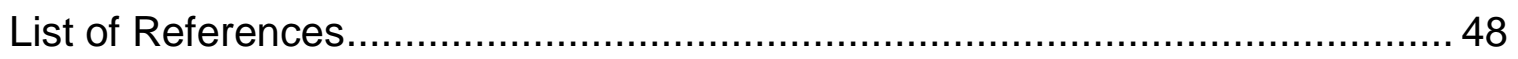




\section{LIST OF FIGURES}

FIGURE 1 - ALTACORP ENERGY COST (MAWDSLEY AND ESPEY, 2011) ....................... 2

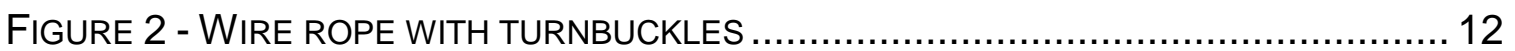

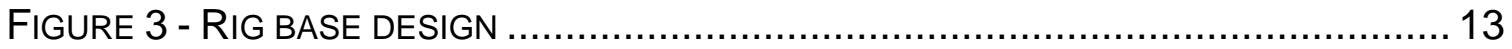

FIGURE 4 - VERTICAL GUIDE RAILS, MOTOR MOUNT, DRILL MOTOR............................. 14

FIGURE 5 - MOTOR MOUNT WITH RECESSED FLANGE ......................................... 14

FIGURE 6 - ALUMINUM EXTRUSION, SIDE VIEW ............................................... 15

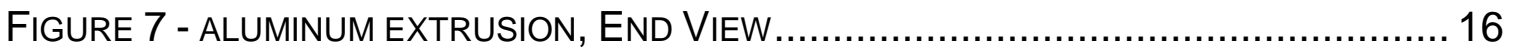

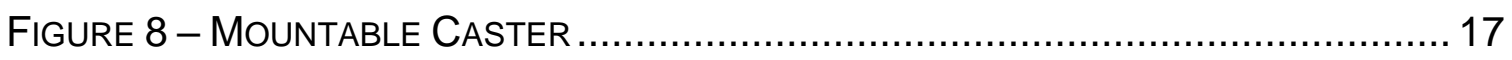

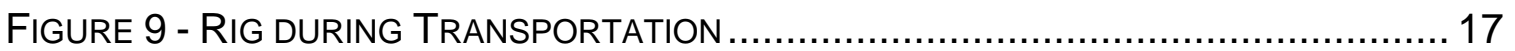

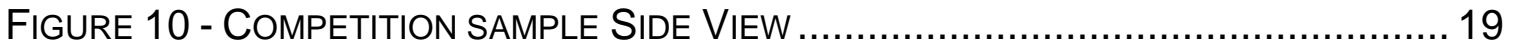

Figure 11 - Competition SAMPLE DeCONSTRUCtED ….................................... 19

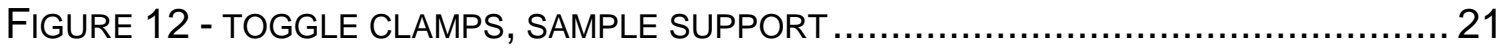

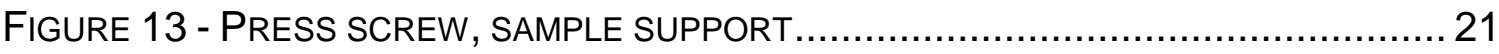

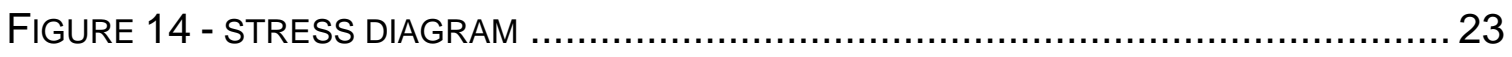

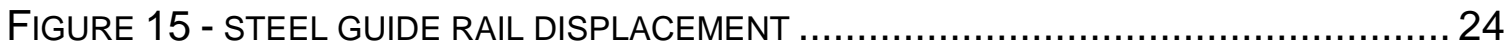

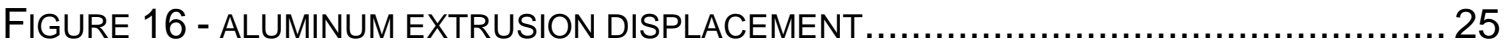

FIGURE 17- POSITION CONTROL MOTOR, COUNTERWEIGHT .................................. 27

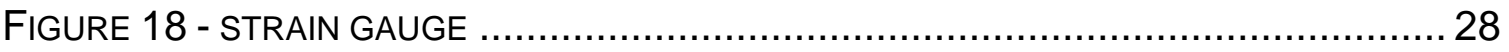

FIGURE 19 - MOTOR MOUNT ITERATIONS, EARLY (LEFT) AND LOW-PROFILE (RIGHT) .... 29

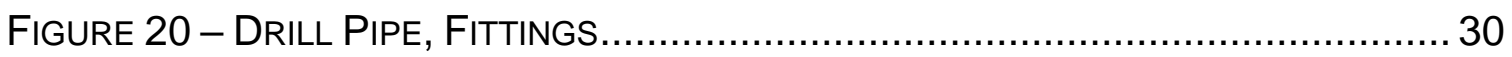

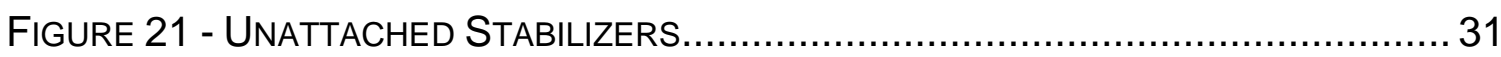

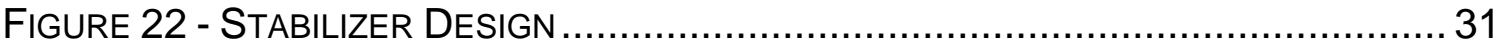

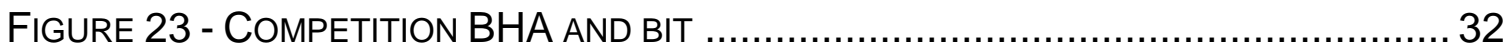

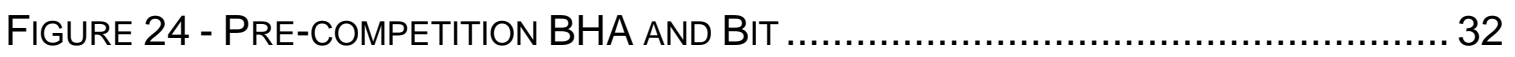

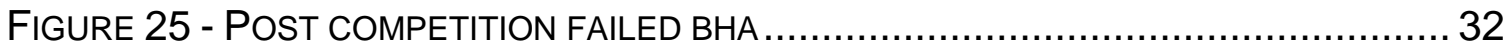

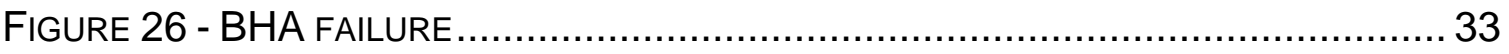

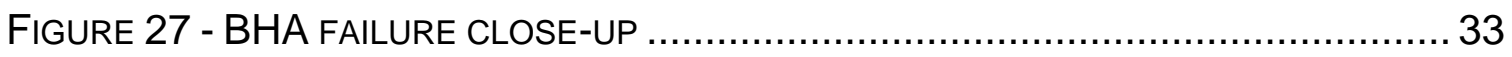

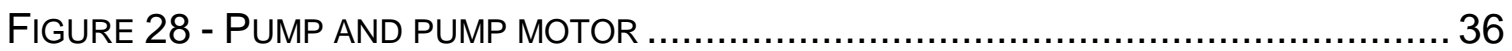

FIGURE 29 - FILTRATION AND CIRCULATION SYSTEM ........................................... 37

Figure 30 -EARLy (Left) AND Competition (RIGHT) BELL NiPPLES....................... 38 


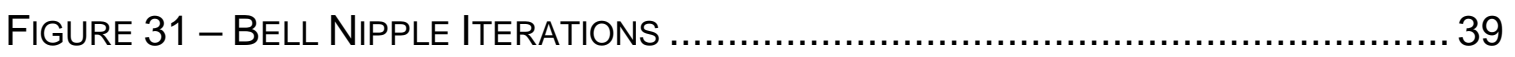

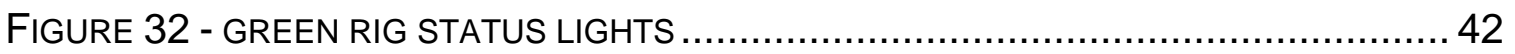

FIGURE 33 - YELLOW RIG STATUS LIGHTS ................................................... 43

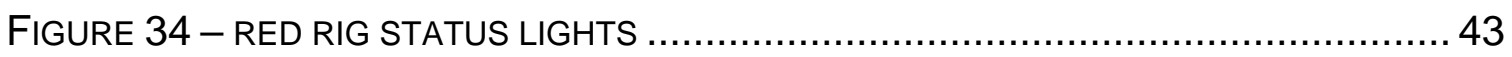

\section{LIST OF TABLES}

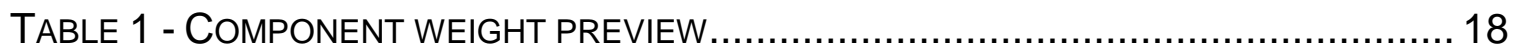

TABLE 2 - Mud HydRaUliCS (BILGesu et AL. 2017) ............................................ 35 


\section{BACKGROUND}

\subsection{ENERGY}

The quality of life in both developing and developed nations is intrinsically linked to energy consumption, which is heavily dependent on the production and consumption of hydrocarbons. Hydrocarbons are by far the most cost-effective form of energy, with renewables often requiring government subsidies to maintain their energy production. It is not practical to assume that developing nations will use their capital to install and maintain alternative sources of energy when a less expensive option is already in widespread practice (Mawdsley and Espey, 2011).

In the case of more developed nations, such as Germany, there has been an enormous movement in the last decade to remove dependence on nonrenewables. In 2010, Germany declared their goal to cut carbon emissions by 40 percent by 2020 (Talbot, 2013). In addition, due to the inherent safety concerns that are currently associated with nuclear power, they were intent on shutting down all of their nuclear power plants by 2022. Government subsidies and locked-in energy prices made developing renewable energy possible for individual citizens, and Germany was well on its way to this unprecedented reduction in emissions. However, Germany faced a problem that was somewhat unexpected: massive unreliability of energy output. On particularly sunny or windy days, when renewable power sources surged, the power grid that was in place wasn't equipped to handle the excess electricity (Durden, 2013).

Given that the German electrical grid is years ahead of most countries and was still unable to handle this overflow, it seems that the idea of relying solely on wind and solar may not be as simple as installing the turbines and panels. On the other hand, on days where renewables didn't provide enough energy, the country had to resort to the traditional methods. In the case of needing a "standby" fuel source to even out renewable production, Germany relies heavily on coal, which is easier to store than oil or natural gas, but also produces more carbon emissions (Martin, 2016). 
Thus far, renewable energy feasibility has been the topic of discussion more than the actual cost associated with that energy. In a study done by AltaCorp Capital in 2011 , using a cost of $\$ 50 /$ tonne for $\mathrm{CO}_{2}$ emitted, the overall cost of each main energy source was discovered. The overall costs of hydrocarbon sources were significantly lower than the other forms of energy production, with the lowest overall cost for energy in natural gas, which will play a major role in energy production. The general trend, however, shows that hydrocarbons that are accessed by drilling are more cost effective than those attained by other means. The cost breakdown can be seen below in Figure 1.

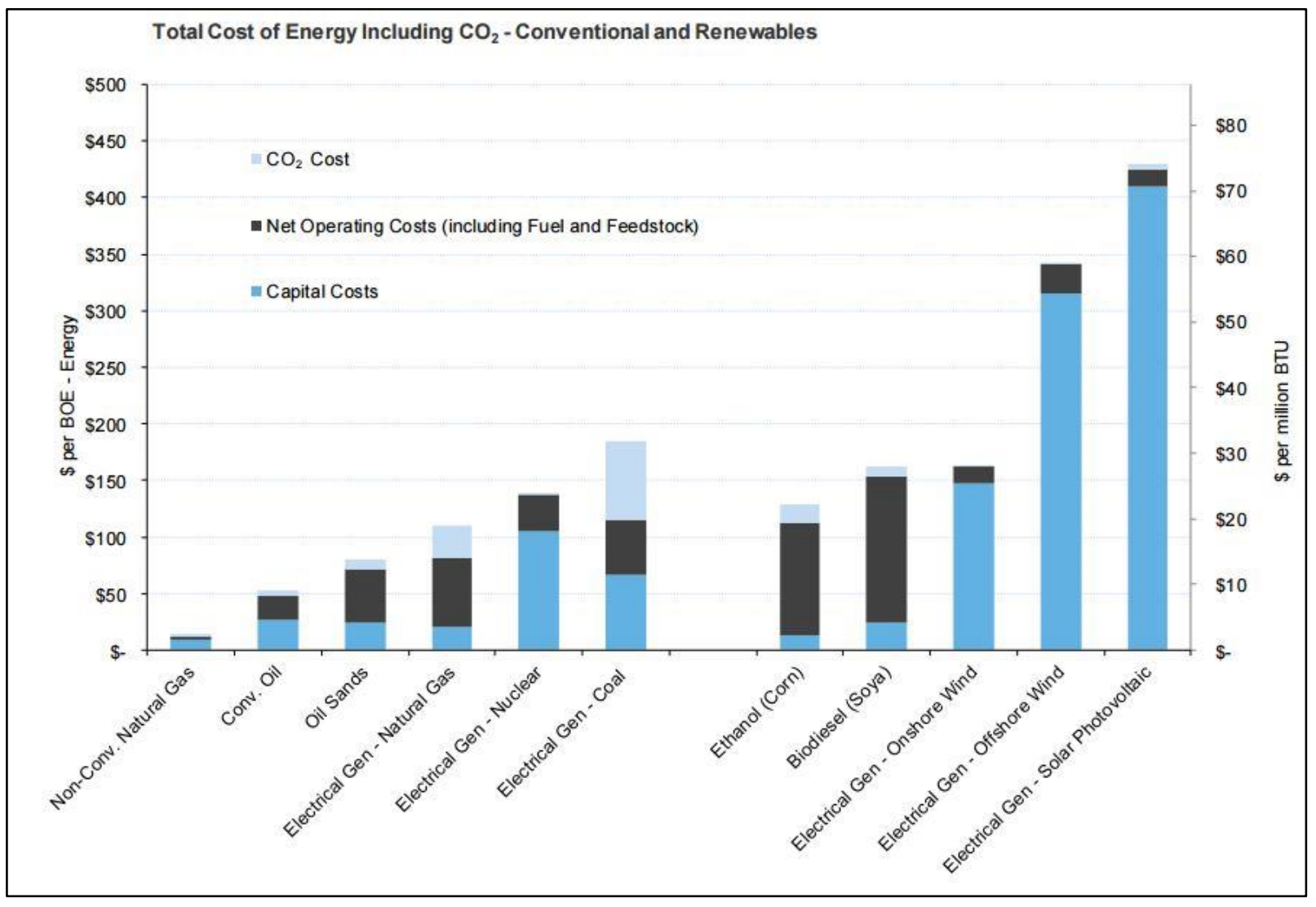

FIGURE 1 - ALTACORP ENERGY COST (MAWDSLEY AND ESPEY, 2011)

The energy landscape of the world indicates that hydrocarbons, and particularly natural gas, will continue to play a major role in providing a stable fuel source to both developing and developed nations. Since these sources will continue to be a necessity, researching methods of accessing these sources more efficiently and 
more safely will also be required. As such, the Drillbotics competition provided a platform to study the design and structural analysis of a lab-scale drilling rig, with the intention to promote rig automation on a small scale that can then be applied within the drilling industry.

\subsection{DRILLING PROCESS}

The objective of a drilling operation is to produce a wellbore that is ready and capable of producing and isolating hydrocarbons. While many techniques and equipment vary rig to rig, these basic principles are widely used for standard drilling. From using a "spring pole" and a variety of bits or chisels to seek shallow groundwater, to the massive rotary drilling rigs used in today's industry, the technology used in the process of delving into the earth has changed considerably in the last 200 years. Transitioning from an impact-style drilling to rotary based, with the ability to circulate fluids to clear away cuttings, dramatically changed the process of drilling for hydrocarbons. While some cable tool rigs are still used, the majority of drilling operations that take place currently employ rotary rigs, allowing for the development of deeper wells (De Wardt, 2012).

Typically, the land is cleared prior to moving a rig to the location, and a drilling pad is set up for the one or multiple wells to be drilled from that location. The supporting structures and equipment, such as the pit, tanks, and compressors, are prepared on site. There are different methods and configurations for wells once drilling has commenced, but typically there is a set of conductor casing set in the shallow formations to maintain control of the loose strata near the surface, followed by surface casing to isolate the well from groundwater. As each set of casing is run into the hole, the annulus between the casing and the formation wall is pumped full of cement to isolate the wellbore from the formation. In addition, each time a casing is set to isolate the wellbore from the formations, successively smaller drill bits are used to continue. 


\subsection{DRILL RIG TYPE}

There are two distinct locations where rotary drilling rigs in use today, those used onshore and those used in offshore operations. While much of the equipment and drilling process is very similar, there are some differences between onshore and offshore drilling, with the most obvious being how they are supported.

Onshore rigs, whether they are conventional or mobile, often have the benefit of being set up on the ground over the target hydrocarbon reserve. There are some circumstances that can prevent the rig from setting up directly above the reservoir, such as surface topography or surface rights. However, new technology is in development to mitigate this setback. One of the technologies that provides a higher degree of mobility in drill rigs is directional drilling. Directional drilling is the process of steering the drill bit to the target formation using Steering While Drilling techniques or technologies. The advancements in this technology have allowed drill rigs to drill multiple wells from one well pad, and to tap into reservoirs that could not previously be reached. Onshore rigs are most often classified based on the depth that they are able to drill to, as well as the overall mobility of the rig. Conventional onshore rigs are those that must be disassembled and reassembled between each drilling location, whereas mobile rigs are those that are mounted to tracks or wheeled trucks and are capable of moving from location to location without fully disassembling (Al-Azani, 2014).

Offshore rigs can employ the same techniques to access difficult reservoirs, but they are supported in one of two ways, bottom-supported and floating units. As the names imply, bottom-supported rigs, typically used in shallower waters, have support columns that rest on the sea floor, whereas floating units are less permanent structures and use engines to keep them in the correct position while drilling. There is also a distinction between offshore rigs based on their mobility and the depth of the sea bed (Al-Azani, 2014).

In general, necessary characteristics of any rotary based drilling platform include a rig's ability to rotate the drill stem, to apply weight to the bit, and to circulate cuttings out of the hole. The rotation imparted to the drill stem is achieved using 
either a top drive motor or a rotating platform built into the rig, commonly called a rotary table. Top drive motors allow some degree of flexibility in allowing the operator to add multiple lengths, or joints, of drill pipe at a time, which reduces the time it takes to break a connection and continue drilling. The penetration of a drilling rig is dependent on both rotation and the weight applied to the bit. In order to maintain a safe and efficient weight, drilling operators measure and control the amount of the drill stem that is being suspended, with the remainder being applied directly as weight on the bit. In addition to an appropriate weight on bit (WOB) and rotational speed, operators are also concerned with the circulation of fluid, ranging from compressed air to polymer-based liquids, which cleans the newly removed rock cuttings away from the bit and returns them to the surface for filtering and disposal. The circulation of fluid also assists in keeping the bit cool and balancing the pressure of fluids within the formation being drilled.

\subsection{DriLling Automation}

Drilling system automation is the process of optimizing operating parameters by use of sensor input and control systems, focused on the downhole activities involved in the drilling of a gas or oil well. The surge in technology over the past several decades has produced systems and processes that will continue to have a substantial impact on the drilling industry. Specifically, the areas of technology that have improved rapidly and have had the biggest impact on the automation of drilling are sensors, computing techniques, and processing systems. These advancements, when applied to any of the various processes in drilling, allow for minimal human intervention, reduced safety risks, and allow for maximum efficiency while drilling (Macpherson et al, 2013).

In recent decades, there has been a surge in the development and use of different automation techniques within the drilling industry. This is in part due to the relatively high risk of drilling operations, where heavy machinery and personnel must work together in close proximity in a variety of conditions (Thorogood et al, 2009). The application of automation technologies has had a significant impact on other industries' safety records, such as the automotive and logging industries, 
which were two of the first to adopt the principals of automation. As an example, timber logging operations in Sweden began mechanizing tasks for both chainsaw and logging-machine operators, and saw drops in accident frequency of $48 \%$ and 70\% respectively, between 1970 and 1990 (Axelsson, 1998).

An important distinction to make between rig automation and drilling automation is that rig automation, much like the automation seen in the automotive industry, involves the combination of hardware and software to remove human involvement from a process. Limited software directs machinery for a specific purpose, and the emphasis is often on the hardware that constructs or fulfills a specific role. Rig automation is very similar, and has been much more widespread than drilling automation, with the focus on improving and mechanizing the surface activities of a drilling operation (Technology, Electrical, 2015). Drilling automation, on the other hand, involves automating the process of drilling downhole, not automating processes that take place on the surface. Remote connectivity is already considered a prime component to the automation of other industries, but because there is no possibility for human involvement downhole, this technology is often overlooked as being a contributor towards automating the drilling process. Directional drilling, logging while drilling, and offsite drilling are all examples of drilling automation, because they employ remote connectivity to access data, process it, and then decisions are made by either algorithms or operators (Lund et al, 2007). 


\section{OBJECTIVES}

\subsection{GeneraL}

The primary objective of this research was to design, construct, and test a fully automated laboratory-scale drilling platform, in conjunction with the constraints and guidelines given by the DSATS committee within the Society of Petroleum Engineers (SPE) for the Drillbotics competition, which will be explained in greater detail in section 2.2. This project and the associated research investigates automation techniques for drilling operations, along with the analysis involved in building an automated pilot-scale drilling platform. The outcome from this research is an investigation of feasible technologies and techniques that can be used to automate a pilot-scale drilling rig, with the intent that these practices may provide insight into the construction or procedures of full scale rigs. The research area focuses on land based drilling rigs, and testing of the rig consists of formations typically found in drilling operations.

Previous research in this field has partially addressed the need for automation, and some contributors have pointed to steps that can be taken to automate a rig, without demonstrating any significant amount of detail (Zamora and Geehan, 2013). That research does not offer a significant amount of practical applications that can be taken to systematically automate functions of a drilling operation. While there is fundamental value in a roadmap to improving drilling performance, there is also a need for testing and analysis of new techniques that could lay the foundation for future operations. In the absence of discovering new technologies, reanalyzing existing procedures and systems may also lead to insight into how those processes could be improved upon. In order to determine what systems are able to be automated, and which that are already automated can be improved, components of semi-automated drilling rigs were examined and, if possible, tested with the proposed rig to determine feasibility. Many of these components have become more widely available in recent years due to the advances in sensor and processing technology, as previously mentioned. 


\subsection{DSATS DRILLBOTICS COMPETITION}

The purpose of the Drilling Systems Automation Technical Section (DSATS) committee is to "accelerate the development and implementation of systems automation in the well drilling industry". To this end, the committee developed a competition, called Drillbotics, amongst Universities with Petroleum and Natural Gas Engineering departments to design and build a rig, approximately seven feet tall, which is capable of drilling completely autonomously. Students were to submit a design proposal in the Fall semester, and the five teams with the best proposals were chosen to build their rig and test it at the end of the Spring semester. The budget for the rig was not to exceed $\$ 10,000$, so the teams that did not have a rig from the previous year had to balance building the rig with the systems of automation that were to be used with it. Additional constraints placed on the teams in Phase 2 were the use of a provided drill bit, and a drill pipe made of thin-walled aluminum, along with a maximum Weight on Bit (WOB) of $20 \mathrm{lbs}$. West Virginia University's Drillbotics team submitted their proposal in December and was selected to compete in the second portion of this competition.

The constraints placed on the Drillbotics competition by the DSATS committee most closely resembled the limitations of land-based drilling rigs, and so the overall structure of the rig was made to emulate mobile land rigs. The most important constraints that were given were that the rig height, mobility, and the use of the provided bit and drill stem. Thus, designs and practices concurrent with land-based drilling were the focus of this research. 


\section{METHODOLOGY}

\subsection{LAB SCALE DESIGN}

The steps taken to complete both this research and the competition followed a similar timeline, specifically the majority of the theoretical design was completed in the Fall Semester of 2015, and the entirety of the construction of the rig was completed in the Spring Semester. In order to design the rig, an analysis was first performed for a variety of materials that could be used to construct the rig. Included in the analysis were aluminum extrusions, steel, wood, and 3-D printed plastic. Due to the weight requirements, and the necessity for the rig to be able to reconfigure, aluminum extrusions were selected as the primary support material.

After selecting materials that would be used to construct the rig, an intensive analysis was conducted on the thin-walled aluminum drill pipe. Selecting a drill motor that would be unable to shear the drill pipe allowed for the design of a motor mount, and the guide rails that would provide vertical travel. Different materials were considered for the guide rails, but after conducting beam deflection calculations, one-inch precision steel shafts were chosen. With the vertical travel system of the drill stem designed, the supporting structure could be modeled and tested in the software Solidworks.

After verifying that there were no obvious flaws in the physical structure, motors were selected for the hoisting and fluid circulation systems. A counterweight concept was chosen to assist in the designation of the hoisting motor, and a closed loop fluid circulation system was deemed the most realistic compared to industry standards. Utilizing a closed loop system necessitated filtering particulates that might damage the pump, so a passive filtration system was also researched and designed prior to rig construction. Once the physical structure, hoisting, and circulation systems were designed and selected, the accompanying measurement and control systems were researched for the operation and automation of the drilling process. 


\subsection{BUDGET AND CONSIDERATIONS}

A major consideration with industry drilling rigs and with the rig design in this study was the cost of construction and operation. The 2015-2016 Drillbotics competition utilized a $\$ 10,000$ budget constraint to both build the rig and procure the components to automate the drilling process. This budget was implemented both to provide a basis on which to judge every participating team, as well as to simulate industry constraints.

The design and construction of the unit were tested and revised several times until an acceptable solution was achieved, as is standard practice with new technology in industry. Universities that had competed in the previous year were able to use rigs that had already been constructed, still considering the cost of components. This allowed previous researchers to better allocate their budget away from unfeasible or impractical designs. Universities that had supplies or materials from a previous year could then "prototype" designs without having to pay for new materials. As this was the first design for this research, it was necessary to balance the cost of the structure, tools, and control components to stay under budget, and the emphasis on the cost of each component was a critical factor in the design philosophy.

As the objective for this task was automation, not specifically drill rig construction, the controls systems were budgeted for prior to the physical structure, as they were deemed more critical. This necessitated using lightweight and low-cost components to make up the physical structure, and meticulous research and analysis to ensure that the design was economical. For example, wood was used to construct the filtration box and storage tank frame, and cement with a cardboard mold was used as a counterweight because they could be constructed at very low costs. Aluminum extrusions, while being chosen primarily for their versatility, were prone to warping and tearing more than steel, but they were considered non-critical in a competition based on automation. Designing a rig with a non-conservative safety factor for the mechanical structure freed up funds that were instrumental in the success of the rig, but this may not be possible outside a laboratory 
environment. However, the desire to keep the cost of the physical structure low led to the high level of analysis and scrutiny that was conducted for this research, and it ultimately led to a rig that was designed with a liberal factor of safety.

Budget constraints played an important role in the selection of both the physical structure and the control components. The sensor system employed several inexpensive Arduinos to maintain control of the rig, rather than purchasing a full computer with functionality the rig would never use. Sensors were chosen based on the degree of accuracy that would be acceptable, similar to a diminishing returns scenario. Thus, a criticality analysis was conducted for each sensor, such as a flowmeter that could measure down to the $1 / 10^{\text {th }}$ of a gallon per minute (GPM), rather than the flowmeter that was accurate to within $1 / 100^{\text {th }}$ of a GPM and cost significantly more. For flow rates between 2 and 4 GPM that were to be used, this level of accuracy was deemed sufficient. The cost, accuracy, and criticality of each component was weighed before making any purchases, and the final cost reflected that at approximately $\$ 8,000$. When the final design budget was analyzed, it was determined that the overall cost of the rig was split almost exactly in half, $50 \%$ to the structure and supporting components and $50 \%$ to the control and measurement mechanisms. 


\subsection{MECHANICAL DESIGN}

\subsubsection{STRUCTURE}

Since aluminum was chosen over steel, overdesigning the supports for the upright beams was both possible to achieve while maintaining a low weight and necessary to the design to eliminate twisting in the rig. The rig itself has four upright aluminum extrusions, with supports at the top, middle, and bottom to provide for a rigid structure. In addition to these support levels, two sets of crossing wire ropes and turnbuckles were run to keep the upper half of the rig in tension and in the proper position. The steel wire rope that was used was $1 / 4$ inch, which was much stronger than the surrounding aluminum, and great care was taken to guarantee that the four cables were properly tensioned so as not to twist the structure. An example of the wire rope tensioners can be seen below in Figure 2. The initial design for the rig was completed using the drafting software Solidworks, and was continuously updated as changes were made to the rig. An example of the design can be seen in Figure 3, with all wiring and peripherals removed.

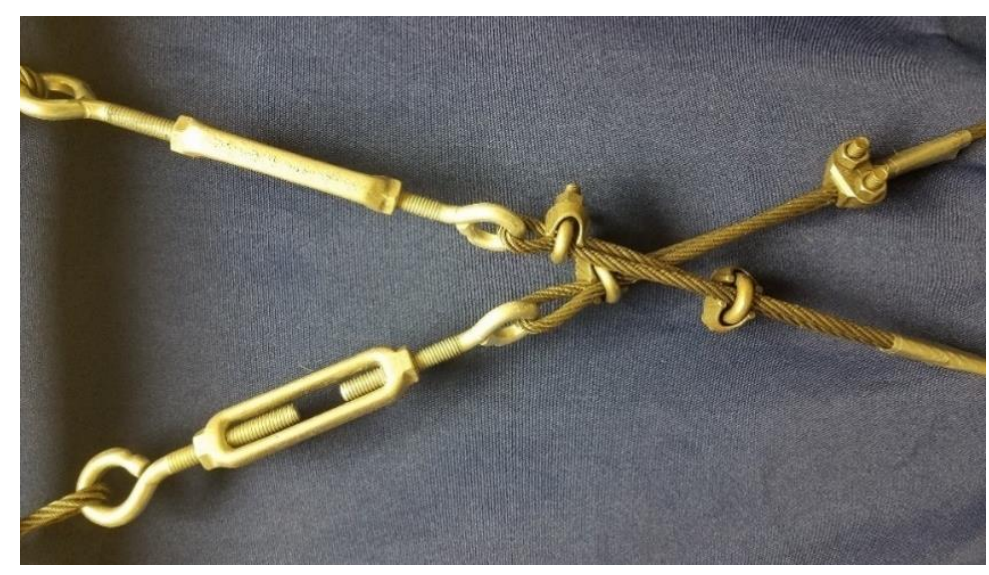

FIGURE 2 - WIRE ROPE WITH TURNBUCKLES 


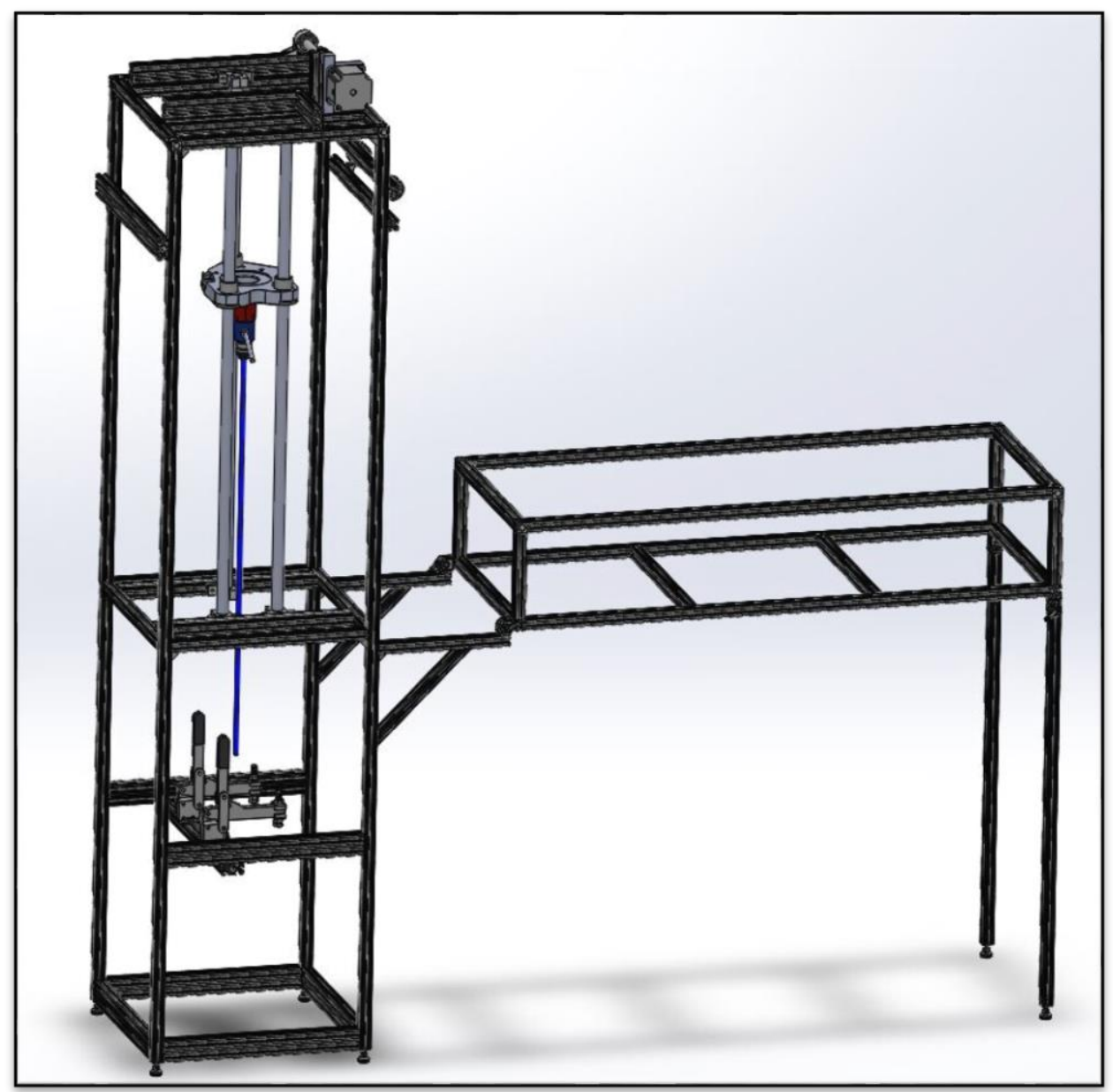

FIGURE 3 - RIG BASE DESIGN

The top and middle support levels also house the guide rails for drill motor travel. In order to ensure straight travel with minimal vibration, 1 -inch precision solid steel shafts were used. It was decided that two shafts might allow the motor mount to drop unevenly and become stuck, and a four-shaft design was more than was necessary, especially given the weight of the four-foot-long bars, so a triangular guide rail design was implemented. To ensure smooth and truly vertical travel, the motor mount was 3-D printed to allow three flange-mounted linear ball bearings to be recessed into the plastic, and these would be oiled periodically to avoid any sticking on the shaft. In total, the three hardened steel shafts contributed to roughly $10 \%$ of the total weight of the rig. The guide shafts and motor mount can be seen in Figures 4 and 5. 


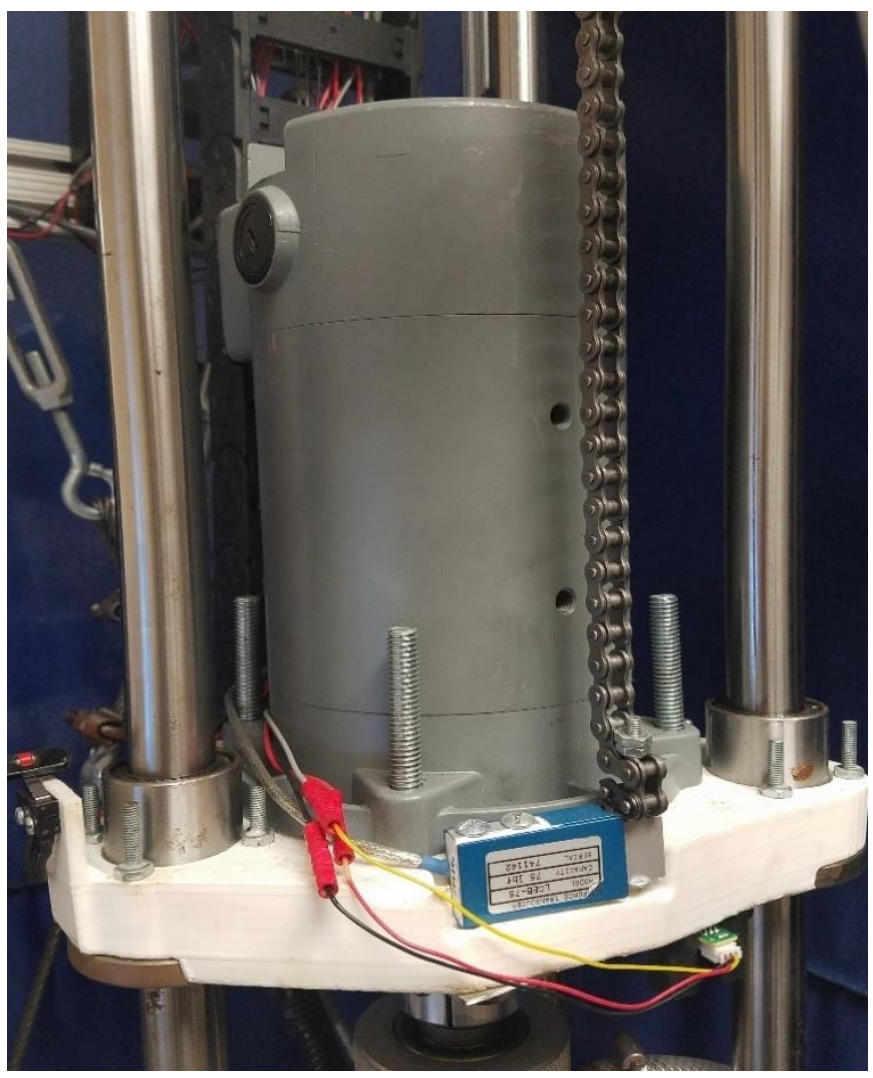

FIGURE 4 - VERTICAL GUIDE RAILS, MOTOR MOUNT, DRILL MOTOR

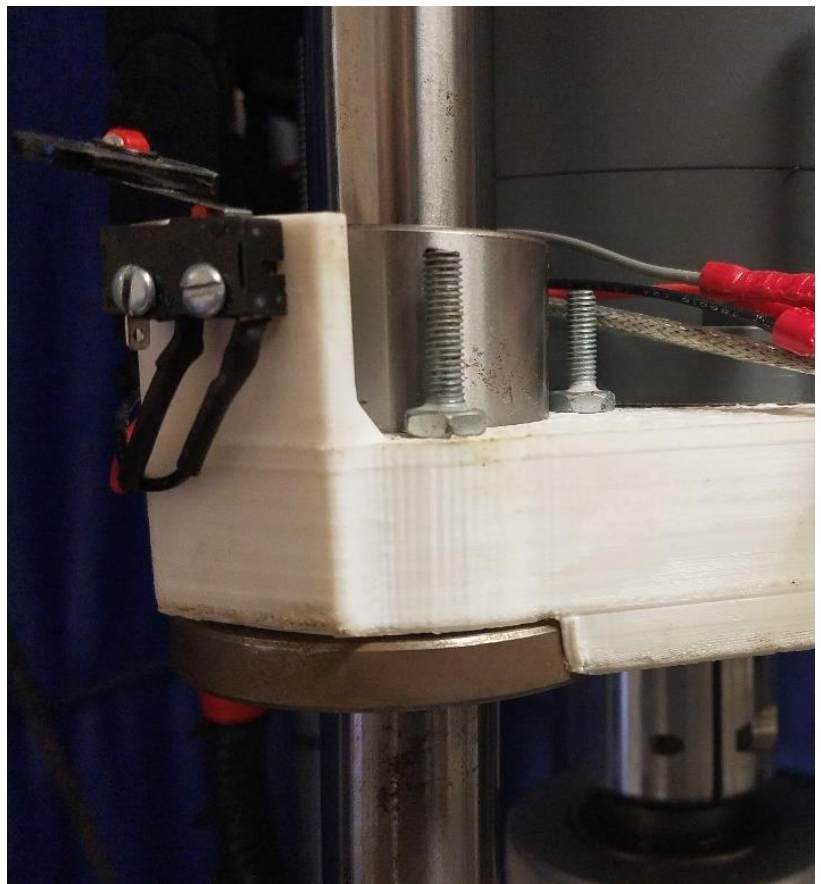

FIGURE 5 - MOTOR MOUNT WITH RECESSED FLANGE 


\subsubsection{CONSTRUCTION MATERIALS}

The majority of the rig itself and the supporting control structure was made with aluminum extrusions. T-slotted aluminum was primarily chosen due to its low weight and adaptability. It was recognized that the initial design, which was submitted in December 2015, would undergo changes as new parts and sensors were tested, so using a material that is easy to machine and easy to reconfigure was essential. Wood was used for some peripheral structures to lower cost, along with Plexiglass to waterproof the controls table while still allowing observation while testing. The aluminum used in the rig structure for testing was 6105-T5 aluminum, with an estimated ultimate tensile strength of $45.0 \mathrm{ksi}$ (310 MPa), and a modulus of elasticity of approximately 10,000 ksi (69 GPa), whereas steel has a tensile strength of $58 \mathrm{ksi}(400 \mathrm{MPa})$ and a modulus of elasticity of 29,000 ksi (200 GPa), but it would have weighed 3 times as much as the aluminum (Aluminum 6061-T6 Properties, 2016). An example of the aluminum extrusions can be seen below in Figures 6 and 7 , along with a common connector used with the extrusions.

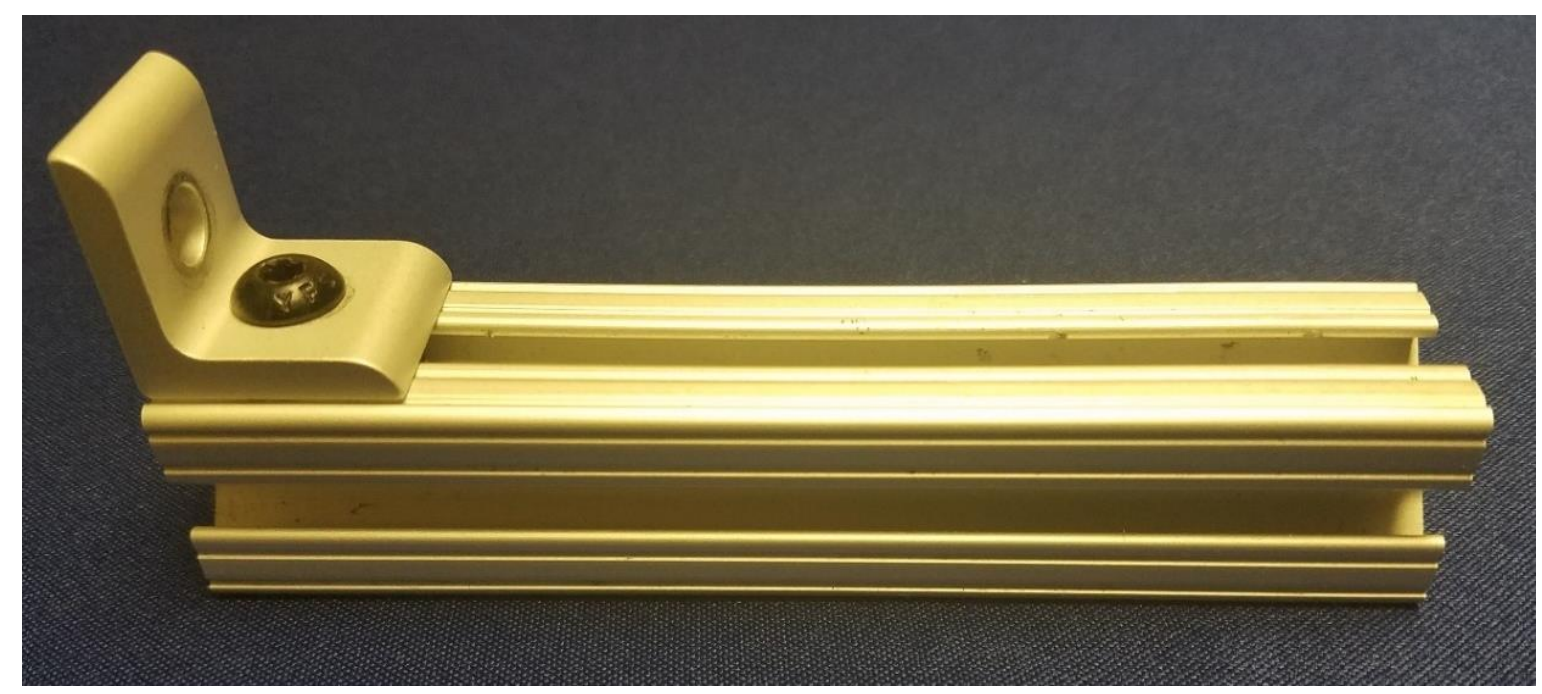

FIGURE 6 - ALUMINUM EXTRUSION, SIDE VIEW 


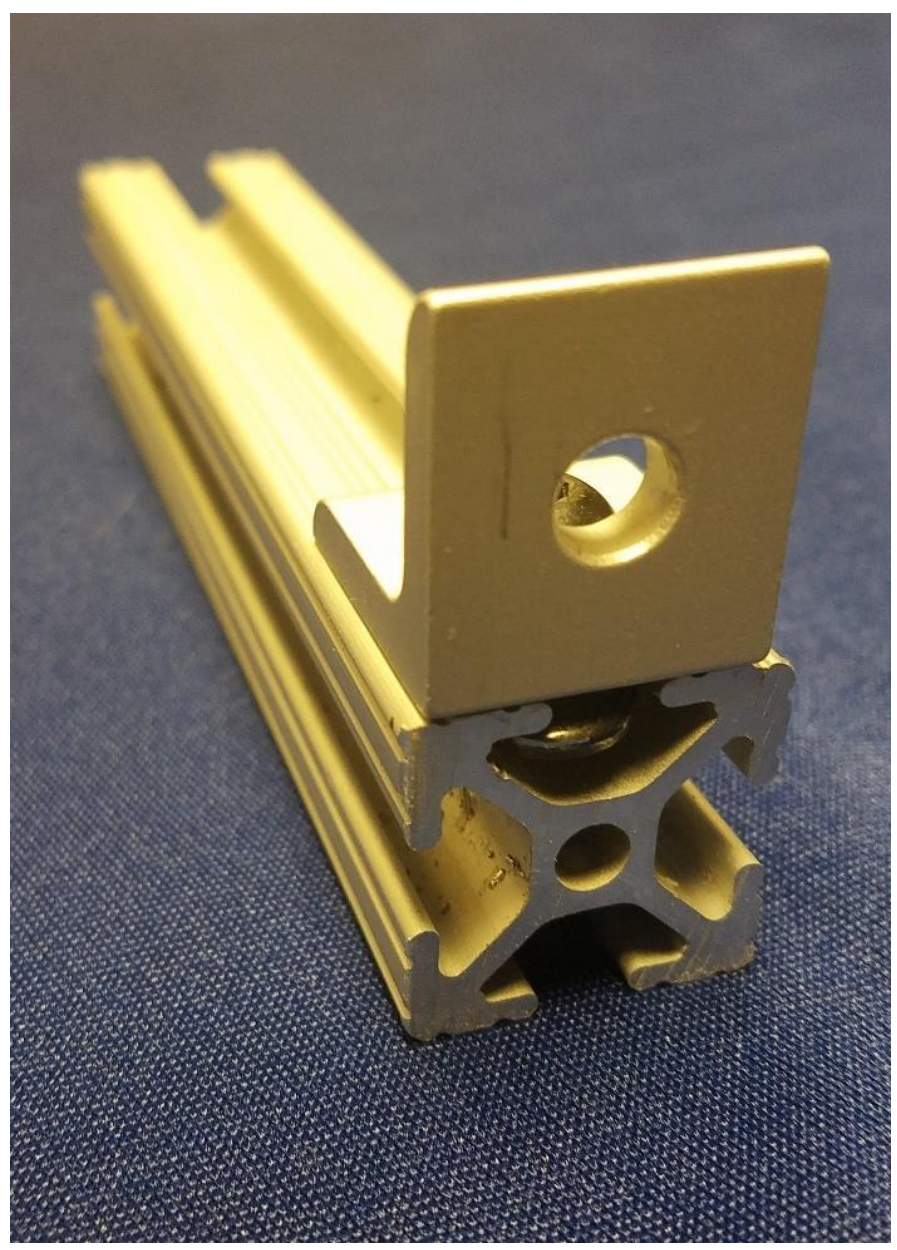

FIGURE 7 - ALUMINUM EXTRUSION, END VIEW

\subsubsection{MOBILITY}

Part of the study was to design a rig that could be easily transported from one location to another. The rig was designed with four heavy-weight casters attached to the side, which were easily removable for times when the rig was set up, but allowed the rig to be transported without any additional assistance. The casters were left on for display purposes during the actual testing, and later the rig was moved out of the testing lab successfully. An example of one of the casters is shown in Figure 8, and Figure 9 shows the rig being transported.

Aluminum was used as the main component to keep the overall weight down, but there were quite a few necessary structures that raised the total weight to 
approximately 300 pounds. While this weight is still very low, even for a pilot-scale drilling platform, the casters were only built to move it around inside a building.

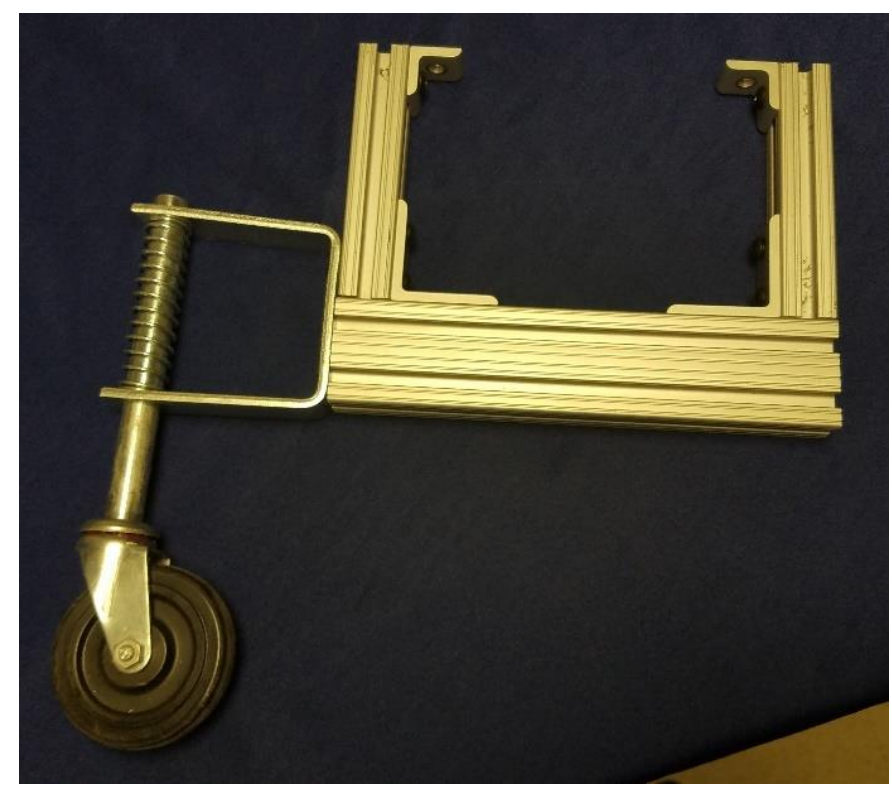

FIGURE 8 - MOUNTABLE CASTER

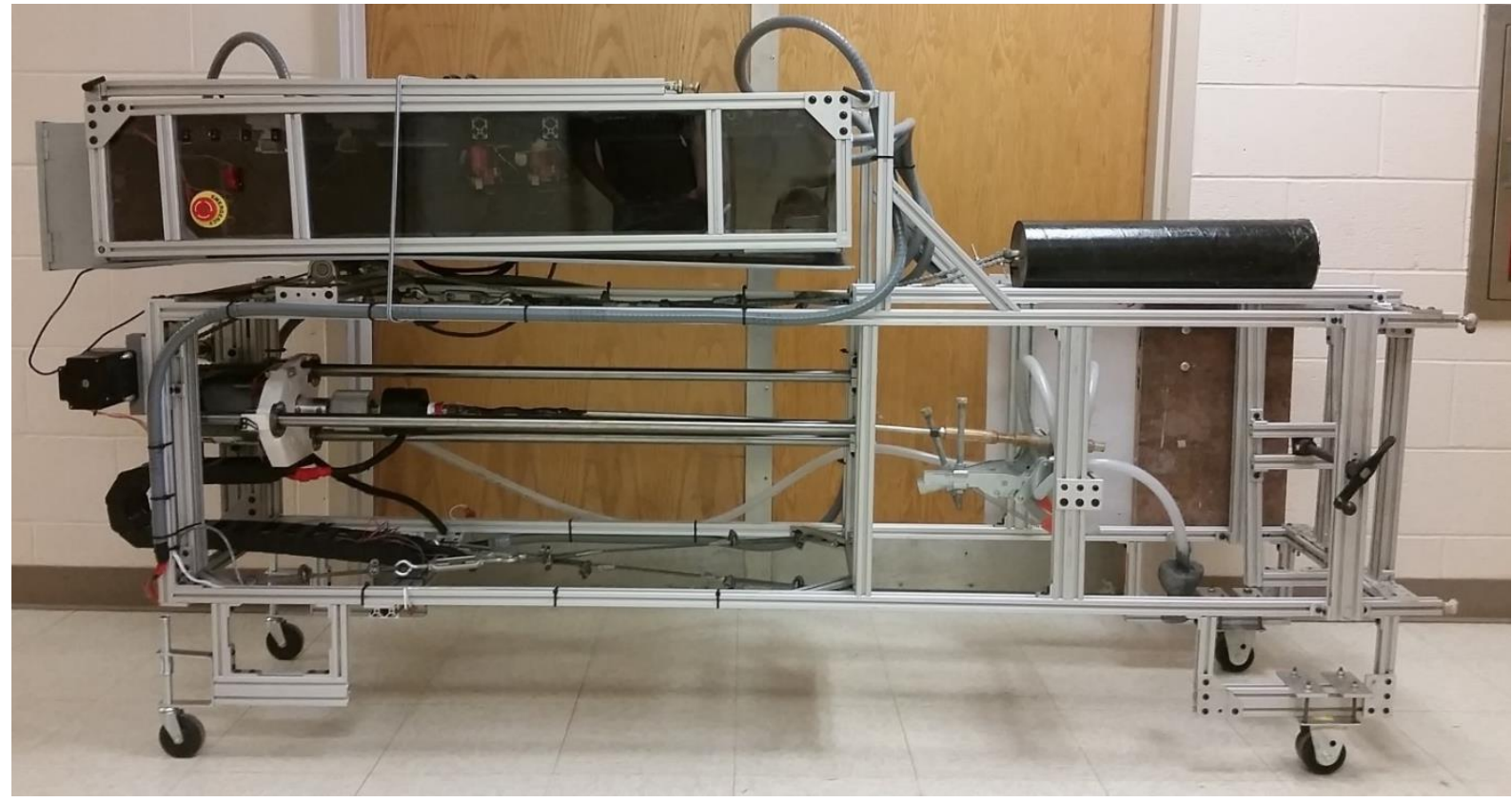

FIGURE 9 - RIG DURING TRANSPORTATION 
As an example of the weight of some non-aluminum components, Table 1 below shows some of the heavier components. Considering the three guide rails as one overall component, it can be shown that nearly half of the weight of the rig came from only five components. The drill, pump, and hoisting motors combined for approximately 77 pounds, but based on the criteria associated with each component, there was no way to reduce that weight with smaller motors. The counterweight, by design, had to match the weight of the drill motor, mount, drillpipe, Bottom Hole Assembly (BHA), and the bit, allowing for significantly less stress on the hoisting motor, but resulting in another 30-pound component.

TABLE 1 - COMPONENT WEIGHT PREVIEW

\begin{tabular}{|c|c|}
\hline Component: & Weight (Ibs) \\
\hline Drill Motor, DC permanent magnet, 1/2 HP & 31 \\
\hline Guide rails, Hardened Steel Shafts x3 & 32 \\
\hline Position Control DC Motor, NEMA 34 & 12 \\
\hline Fluid pump, Pump motor, 3/4 HP & 34 \\
\hline Cement Counter weight & 33 \\
\hline Total: & 142 \\
\hline
\end{tabular}

\subsubsection{SAMPLE SUPPORT}

There were several components provided by the DSATS committee that were required to be used, including the sample that was to be drilled for the official testing. The sample that was provided for testing was simple in design, but posed a unique set of challenges. The test sample utilized 2-to-3-inch-thick, 12-inchsquare pieces of sandstone or siltstone with a single wooden dowel rod inserted between layers to introduce an angle to the formations, as shown in Figure 10. The top two and bottom two layers were sandstone, and a uniaxial compressive strength of around 5,000 psi was expected for these layers. The middle layer was siltstone, but its compressive strength was unknown prior to testing. However, all five layers were encased in a plywood and 2" 4 " box so these rock layers were all unknown prior to testing. Some fluid loss was expected due to imperfect sealing between layers, but the space imparted by the dowel rods amplified that loss. 
Pictures of the competition sample, post drilling and separated, are given below in Figures 10 and 11.

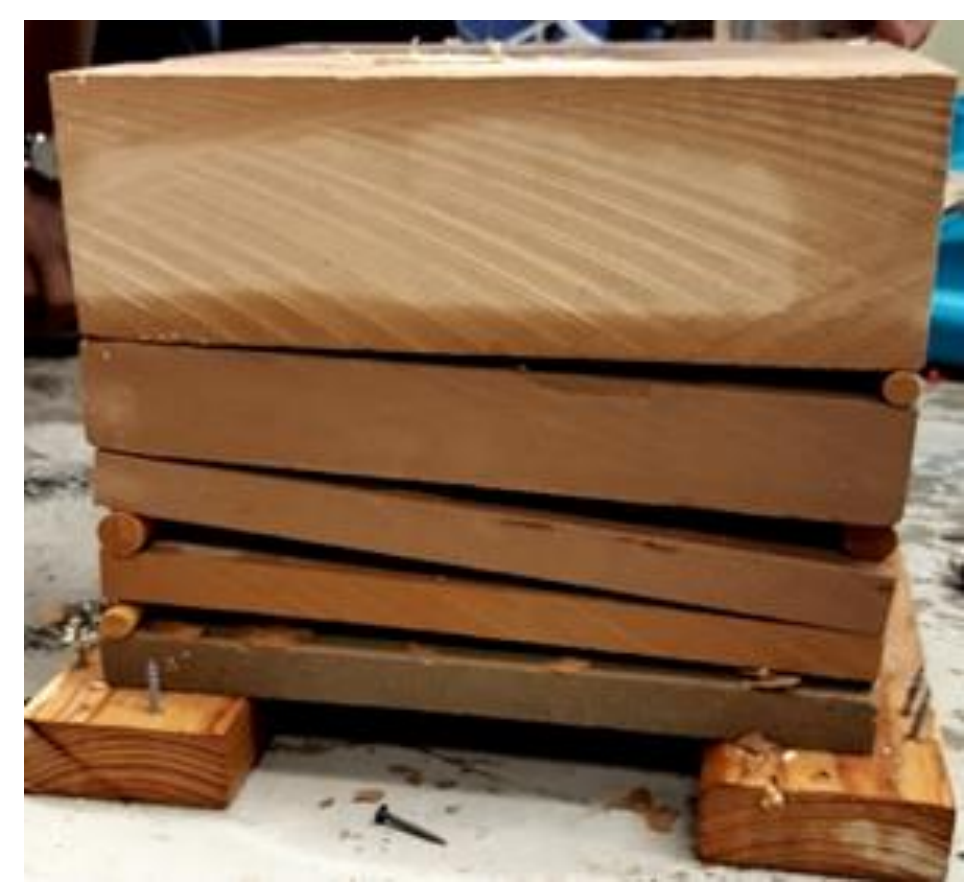

FIGURE 10 - COMPETITION SAMPLE SIDE VIEW

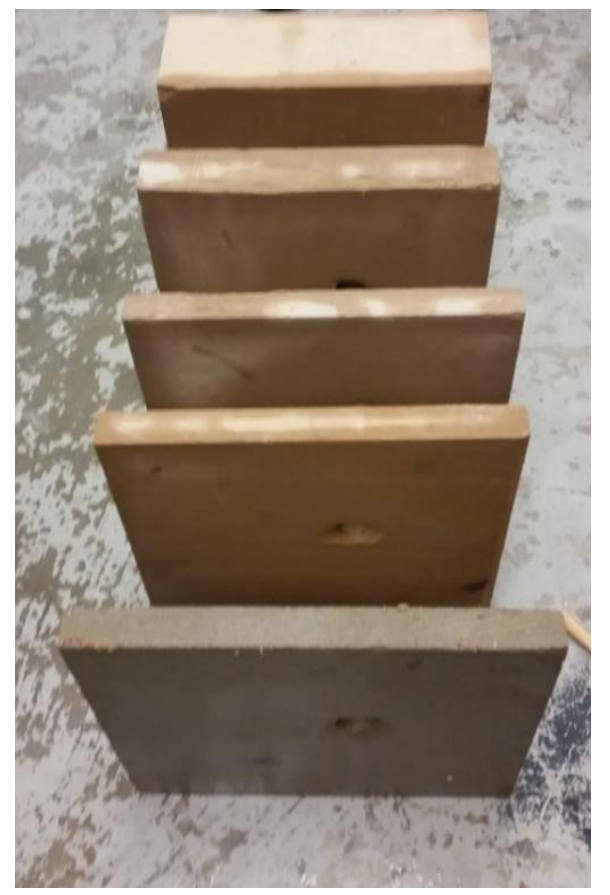

FIGURE 11 - COMPETITION SAMPLE DECONSTRUCTED 
Due to the unknown nature of the competition sample, a separate composite sample was constructed to prepare and test the rig prior to the official testing. This was done in part to test the low factor of safety of the rig, as well as to test the algorithm in samples that contained unexpected layers. The test sample was made using a similar wooden box for support, but contained layers of sandstone, coal, and a much higher compressive strength dolomite, all encased in cement. The rocks that were encased in the test sample were put at extreme angles, 45 degrees in the case of the dolomite, to further challenge the rig to maintain a low-deviation hole. The overall weight of the competition sample was approximately 120 pounds, whereas the weight of the composite test sample was approximately 180 pounds. In addition to creating a sample with extreme scenarios, not knowing what rock strata the rig was drilling gave the the opportunity to interpret the data without bias after drilling the sample.

Due to the weight of the rock samples, it was determined that the rig would provide a "floor" for the sample to sit on, with two hold-down toggle clamps mounted above the sample to secure it. The toggle clamps were each rated to 1,700 pounds of force, and while that was excessive given the weight of the rig, they were the only clamps deemed physically large enough to hold the sample in place. In addition to the toggle clamps, a press screw mounted to an aluminum frame was used to secure the sample in the horizontal plane. While the sample box was built to allow it to be placed on the floor and drilled without damaging the floor, it was determined that the added weight on the lightweight rig would help dampen vibrations. The toggle clamps can be seen in Figure 12, with one clamp in each position, and the press screw can be seen in Figure 13. 


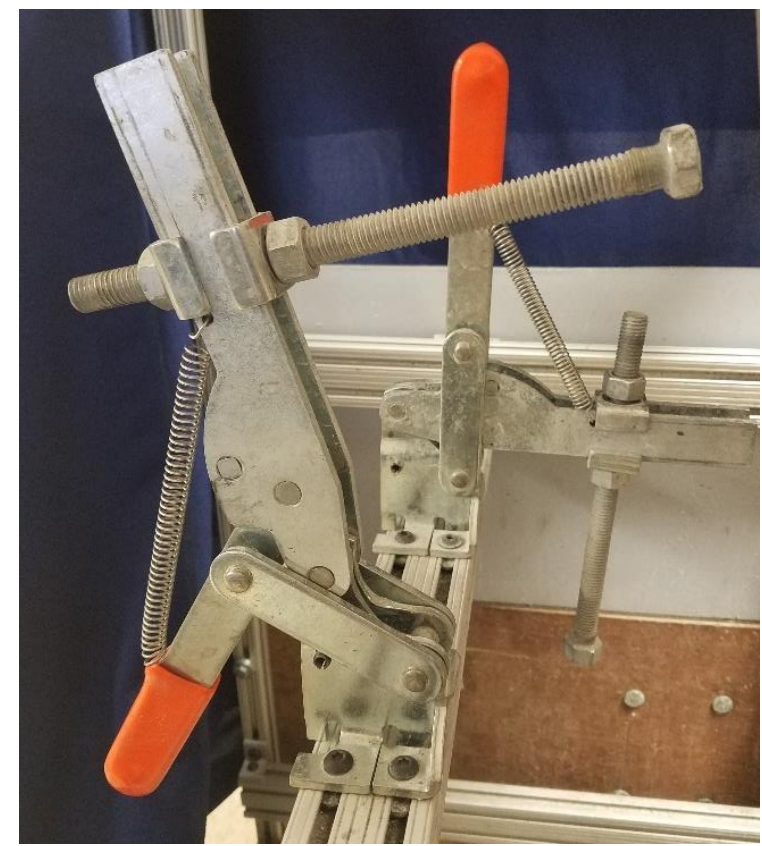

FIGURE 12 - TOGGLE CLAMPS, SAMPLE SUPPORT

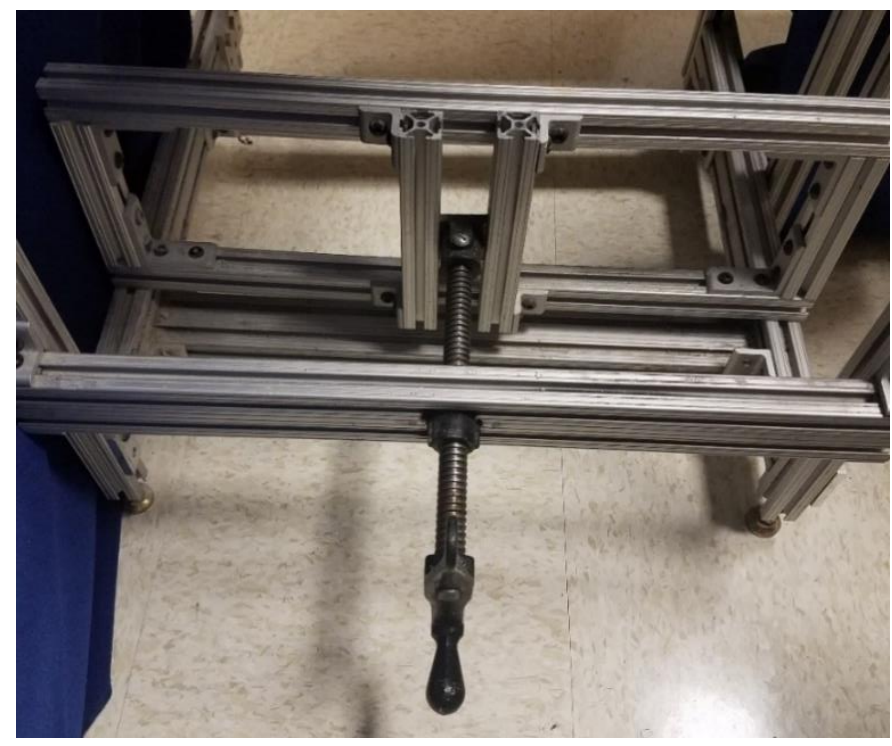

FIGURE 13 - PRESS SCREW, SAMPLE SUPPORT

\subsubsection{TORQUE AND COMBINED LOADING}

Prior to the motor selection, a mechanical analysis was performed on the drill pipe that was to be used for the testing. It was assumed that the thin-walled aluminum drill pipe would be the component most likely to shear, and thus the motor and 
structural component selections were based on this analysis. Industry calculations include the axial and hoop stresses on a drill pipe, along with the shear stresses, because the drill pipes used in industry applications are under extreme internal pressures and compressional loads. The same calculations were used for this research, even though the internal pressure and compressional load would be minimal.

Since the rig would need to be tested prior to the competition, and changing damaged drill pipes would be costly in terms of time, it was determined that a safety factor close to 1.5 would be desirable. An initial maximum shear was determined based on the stall torque of a proposed motor, and in the case of the motor that would eventually be used, it was 50 in-lbs. of torque. After solving for maximum shear, Equation 1 was used to determine whether that motor would be able to shear the pipe, without considering the combined loading scenario initially.

$\tau_{m}=\frac{T * r}{J}=\frac{50 \mathrm{in}-l b . * 0.34 \mathrm{in}}{0.001092 \mathrm{in}^{4}}=15.6 \mathrm{ksi}$

Where $\tau_{m}$ is maximum shear, $T$ is stall torque, $r$ is mean radius of the pipe, and $J$ is the polar moment of inertia. Given that the shear strength of 6061 T6 aluminum is approximately $30 \mathrm{ksi}$, with a yield strength of approximately $40 \mathrm{ksi}$, this motor was appropriately sized (Engineering Toolbox, 2016). Next, the compressional stress, axial stress, and hoop stress were all calculated using Equations 2, 3, and 4.

$$
\begin{aligned}
& \sigma_{\text {comp }}=\frac{F}{A_{\text {alum }}}=\frac{20 \mathrm{lbs} .}{0.04 \mathrm{in}^{2}}=500 \text { psi......................... } \\
& \sigma_{\text {axial }}=\frac{P * r_{m}}{2 * t}=\frac{40 p s i * 0.34 \mathrm{in} .}{2 * 0.7 \mathrm{in} .}=9.7 \mathrm{psi} \\
& \sigma_{\text {hoop }}=\frac{P * r_{m}}{t}=\frac{40 \text { psi*0.34 in. }}{0.7 \text { in }}=19.4 \text { psi }
\end{aligned}
$$


Here $F$ is the compressional force applied to the drill pipe (with a maximum of 20 Ibs.), Aalum is the cross-sectional area of the pipe, $P$ is the internal pressure (which was at most 40 psi at 3 GPM flow), $r_{m}$ is the mean radius, and $t$ is the pipe wall thickness. In order to find the principal stresses, forces acting inward on the pipe would be considered positive, and forces acting outward would be considered negative, as shown in Figure 14.

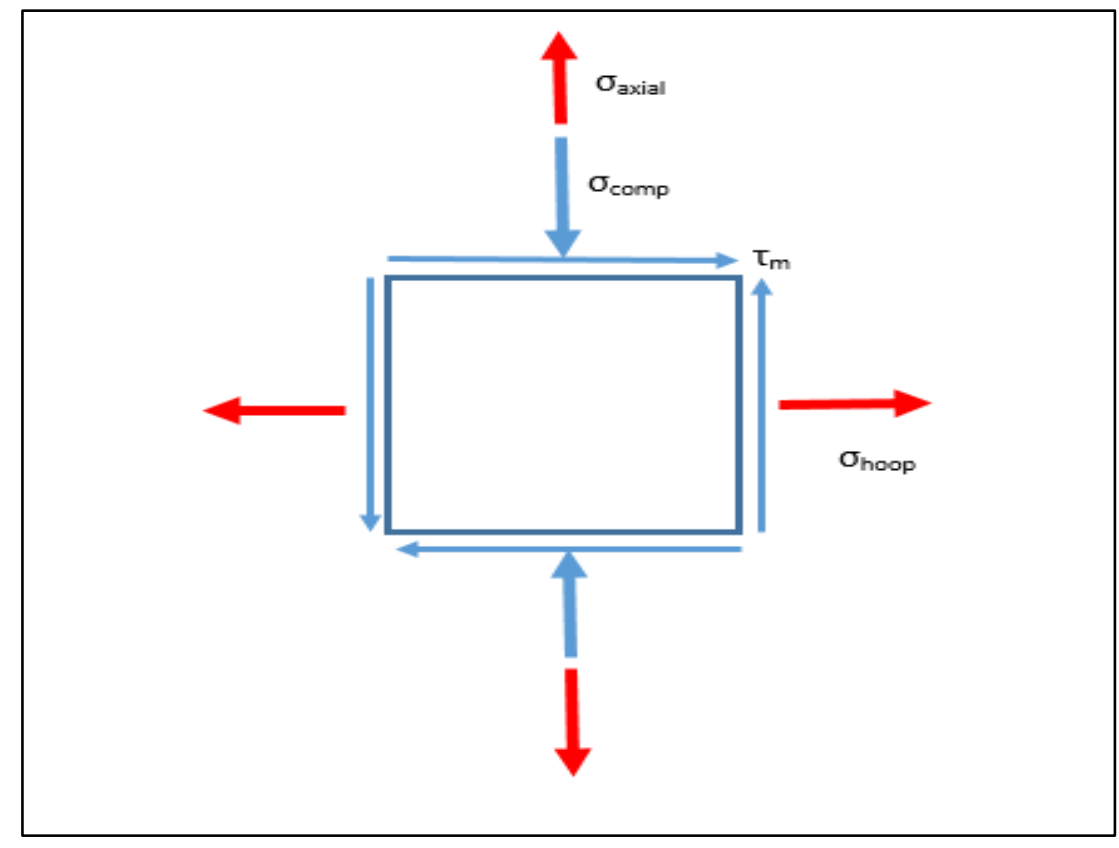

FIGURE 14 - STRESS DIAGRAM

The equations to solve for the principal stresses are given below, along with the equation for the combined stresses and overall safety factor.

$$
\begin{aligned}
& \sigma_{1,2}=\frac{\sigma_{x}+\sigma_{y}}{2} \pm \sqrt{\left(\frac{\sigma_{x}-\sigma_{y}}{2}\right)^{2}+\tau_{m}^{2}} . \\
& \sigma_{c}=\sqrt{\sigma_{1}^{2}-\sigma_{1} \sigma_{2}+\sigma_{2}^{2}} \ldots \ldots \ldots \ldots \ldots \ldots \ldots \ldots \ldots \ldots \ldots \ldots \ldots \ldots \ldots \ldots \ldots \ldots \ldots \ldots \ldots \ldots \ldots \ldots \ldots \\
& n
\end{aligned}
$$


A safety factor of 1.48 allowed for the selection of a $1 / 2 \mathrm{HP}$ permanent magnet DC motor as the main drill motor, providing an RPM range up to 1800, but keeping the stall torque low enough to ensure the integrity of the drill pipe.

To demonstrate that the drill pipe was indeed the critical component, a beam deflection calculation was performed for each of the upright supports that would see the most axial force from the drill motor. These uprights were the three steel guide rails that the motor mount traveled along, as well as the four aluminum extrusions that made up the corner posts of the rig. Given than the steel shafts were 3.6" from the center of the motor, and utilizing the $50 \mathrm{in}-\mathrm{lb}$. stall torque, it was determined that the axial force applied to the shafts would be at most $4.6 \mathrm{lbs}$. The largest deflection would occur with the drill motor in the middle of the 4' shafts, so the deflection calculation was done assuming the motor was 24" down from the top. At that height, and with a polar moment of inertia of $1.69 \mathrm{in}^{4}$ for the shafts, the maximum displacement of the steel would be $5.23 \times 10^{-4}$ inches, as shown in Figure 15.

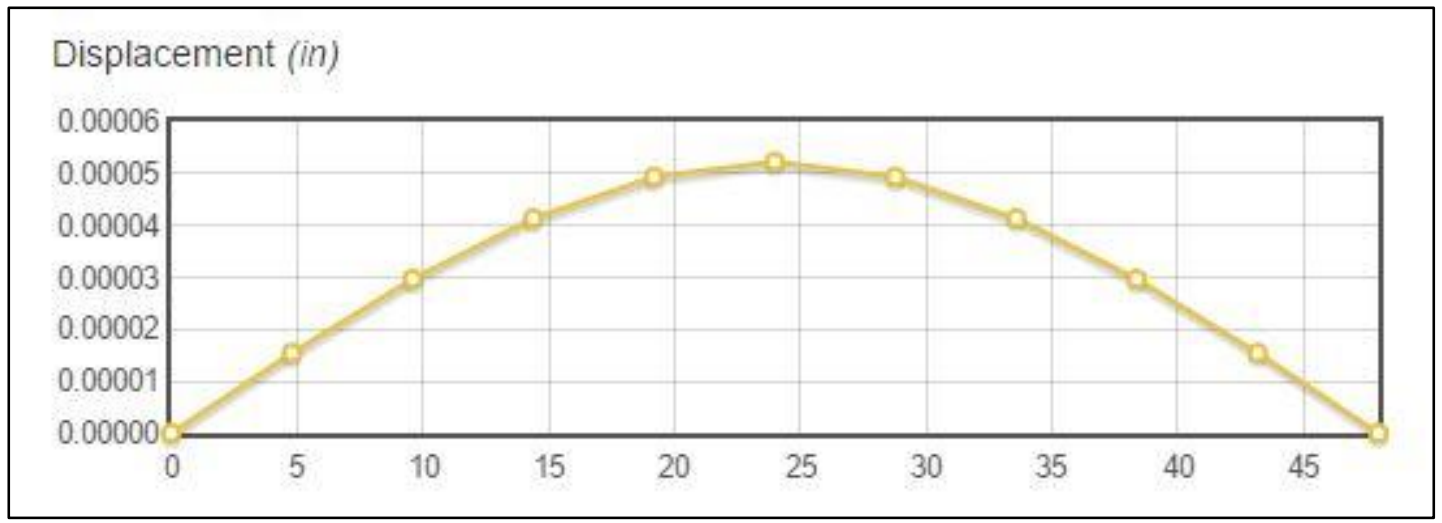

FIGURE 15 - STEEL GUIDE RAIL DISPLACEMENT

The same calculations, done with the 7' aluminum extrusions, given a polar moment of inertia of approximately $0.057 \mathrm{in}^{4}$, resulted in a maximum displacement of approximately $5.96 \times 10^{-2}$ inches at the midpoint of the beam, as shown in Figure 16. 


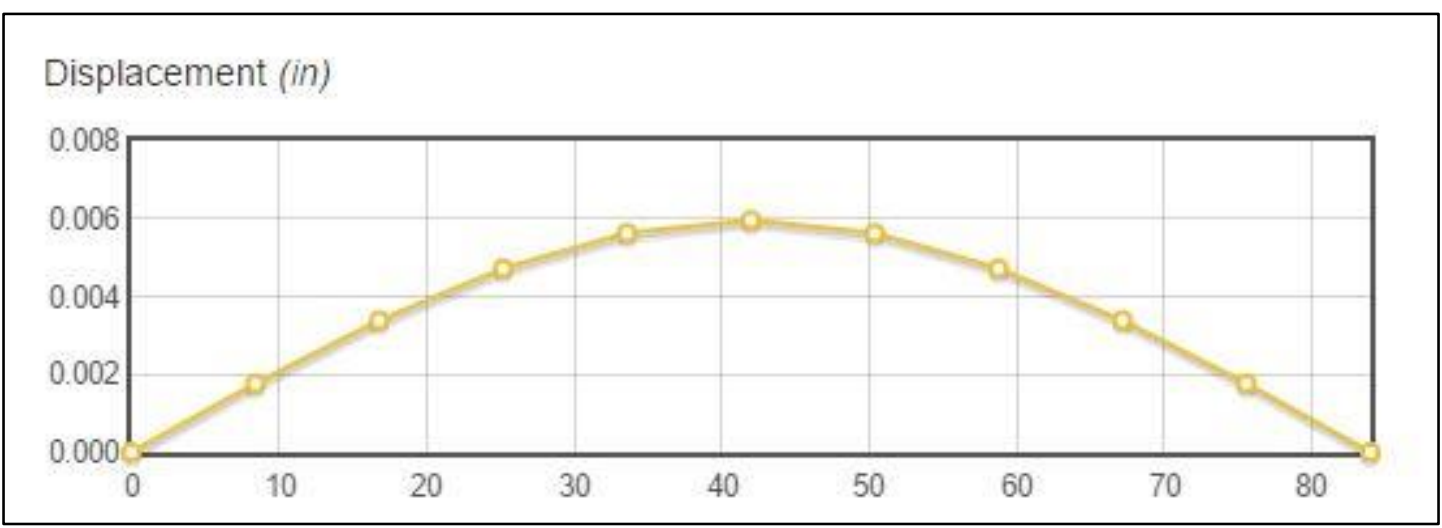

FIGURE 16 - ALUMINUM EXTRUSION DISPLACEMENT

With the displacement of both of these uprights being negligible, it was concluded that the drill pipe was the critical component in the motor design, and the motor that these calculations were performed with was selected.

\subsection{HOISTING SYSTEM}

\subsubsection{MOTOR ANALYSIS AND SELECTION}

The rig utilized a hoisting system similar to that used in industry, in that the system relied on the drill motor being suspended and lowered to advance the drilling, instead of using a piston to push the drill stem into the rock. Using a hoisting system allowed for the approaches that were taken in this research to be directly applicable to industry scale rigs. The most notable differences between the labscale rig and industry rigs were the use of a counterweight, the lack of a traveling block, and the distribution of weight. The design of the pilot-scale rig necessitated the use of a position control motor that was capable of moving in very small steps, while still maintaining the torque required to lift the drill stem. Based on the estimated weight range of the drill stem, a NEMA 34 class DC position control motor was chosen, with a maximum RPM of 720 and 70 in-oz. of torque.

\subsubsection{COUNTERWEIGHT}

In industry rigs, the weight that is applied to the bit is mostly gained from the length of pipe above the bit in the hole. In wells that are thousands of feet deep, there is a significant amount of weight in the pipe above the bit, and normally there is a 
point midway up the drill stem where the load is transferred to the hoisting motor, with the pipe above that point in tension rather than compression. This point is called the neutral point, and lifting or lowering the drill pipe affects where this point is and thus how much weight is applied to the bit. The amount of weight that isn't supported by the bottom is called the "hook load". With the current rig design, there wasn't enough material to provide the maximum 20 lbs Weight on Bit (WOB) below the drill pipe, so the drill motor weight kept the drill pipe in compression to maintain WOB.

Industry rigs generally have a very high hook load and rely on designs incorporating what is called a "traveling block" to lower the amount of power needed by the hoisting motor to raise and lower the drill stem. The traveling block is a series of pulleys around which the steel cable is run, and the traveling block is anchored at the top of the rig at the crown block. The utilization of a system of pulleys gives a significant mechanical advantage, dramatically decreasing the amount of force necessary to move the system. However, the more pulleys present, the farther the hoisting motor has to pull to move an equivalent distance. This can help in more precise movement, but in the case of the rig designed in this study, the position control motor was precise enough.

To lower the drill stem into the hole, industry rigs use a spool of high-strength steel cable, relying entirely on the hoisting motor to hold the weight that isn't supported on the bottom of the hole. The lab-scale rig used a similar hoisting motor and ANSI 35 chain, but relied on a concrete counterweight on the other end of the chain, rather than a spool of extra chain. The unique benefits this provided were that the hoisting motor only had to overcome friction plus the small difference in weight between the drill stem and the counterweight, rather than supporting the weight of the entire drill stem. This provided more precise movement and measurement by the position control motor, resulting in more accurate WOB adjustments and position measurements. Also, the counterweight acted as a safety device in the event that the emergency stop was applied, or if the rig lost power. If power was removed from the system, the counterweight caused the drill stem to remain in 
place, rather than slamming down if the bit was not already on bottom. An image of the counterweight system is shown in Figure 17.

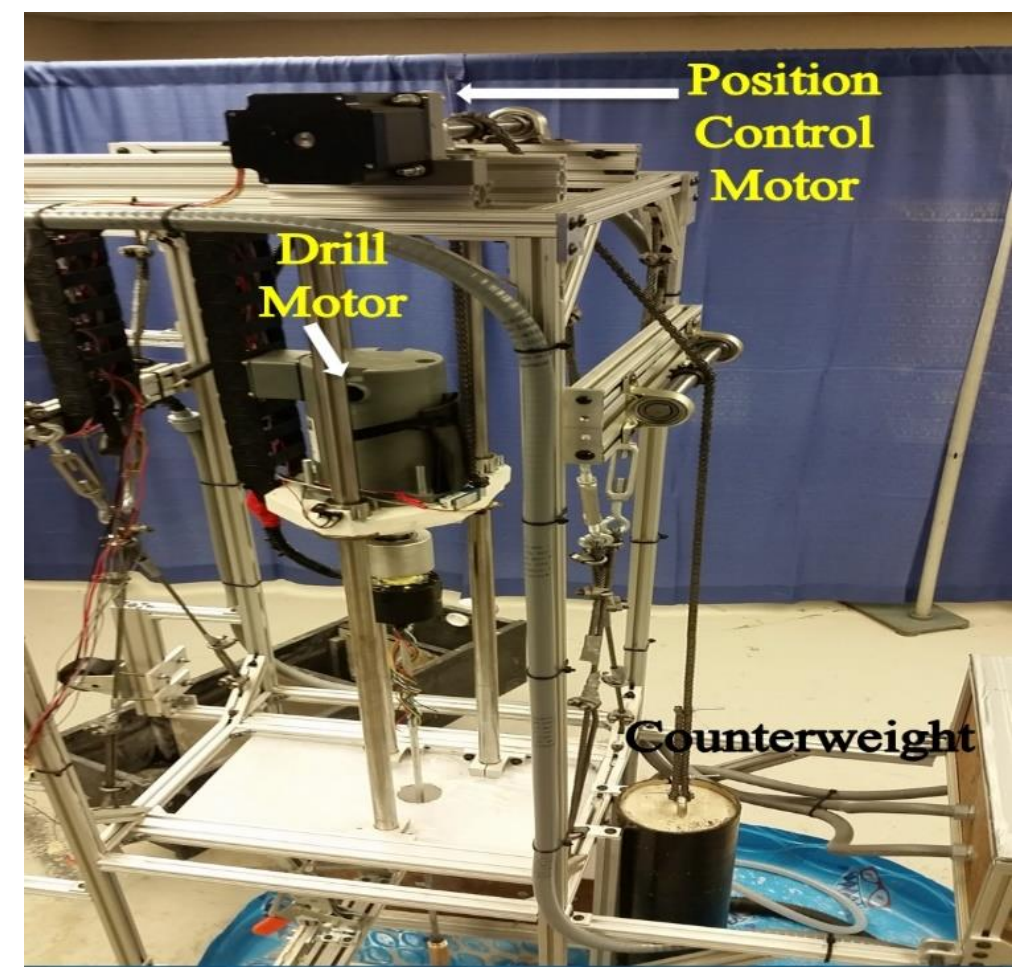

FIGURE 17- POSITION CONTROL MOTOR, COUNTERWEIGHT

\subsubsection{StRAin GAUGE}

The design constraints limited the rig to $20 \mathrm{lbs}$. as the maximum WOB, and maintaining an appropriate WOB was as important to this study as it is with drilling operations in the field. In industry operations, limiting WOB is important to extend the life of a bit, and appropriate WOB for a given formation can increasing drilling rate. To ensure proper WOB for the competition, a strain gauge was mounted to the 3-D printed motor mount, which was then attached to the hoisting chain. The strain that this gauge measured, after the bit was in contact with rock, was directly related to the amount of weight that was applied to the bit, with the remainder being suspended by the counterweight and hoisting motor. This sensor was critical in determining WOB, and because WOB was one of the factors that can affect the Rate of Penetration (ROP), it was also a critical part of the algorithm which 
optimized the drilling performance. A picture of the strain gauge is shown in Figure 18.

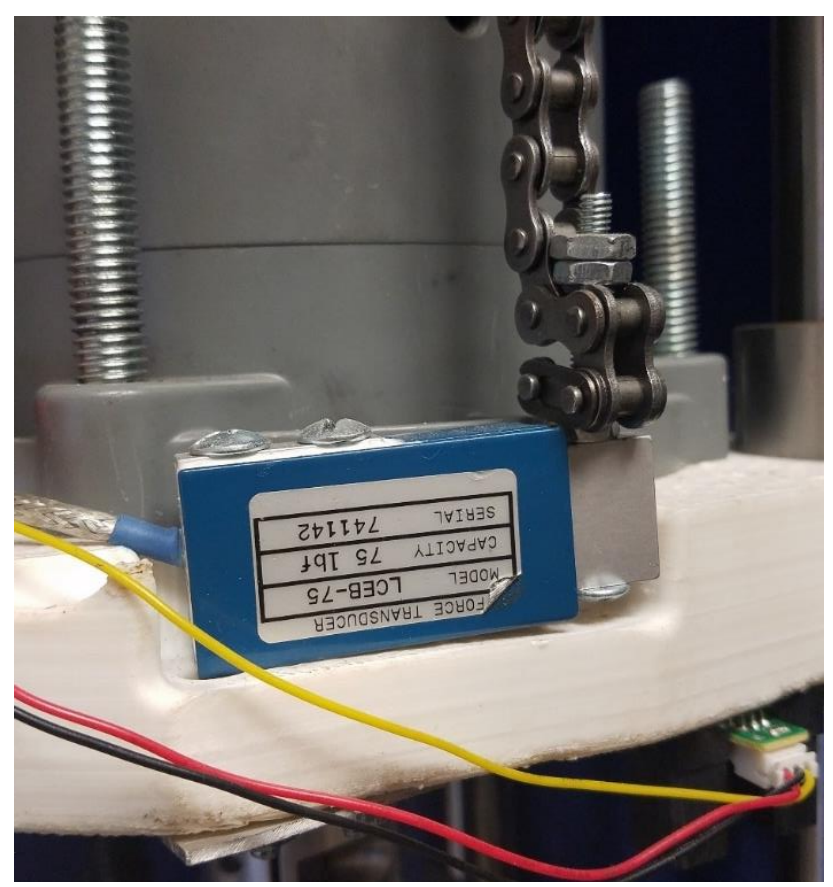

FIGURE 18 - STRAIN GAUGE

\subsection{ROTATIONAL SYSTEM}

\subsubsection{MOTOR MOUNT}

The drill motor mount, along with several other components, were printed with Acrylonitrile Butadiene Styrene (ABS) plastic using a 3-D printer. Four iterations of motor mounts were tested before finalizing the one used in the testing, which by comparison to the previous designs was considered very low-profile. Printing the motor mount in plastic resulted in a very compression-resistant frame that weighed only about one pound. While the overall weight of the mount was low, the strength of the material was more than adequate, housing the mounting points for the strain gauge. Examples of the motor mount are given in Error! Reference source not $\mathbf{f}$ ound. 5 and 18. Examples of the previous iterations can be seen below in Figure 19. 


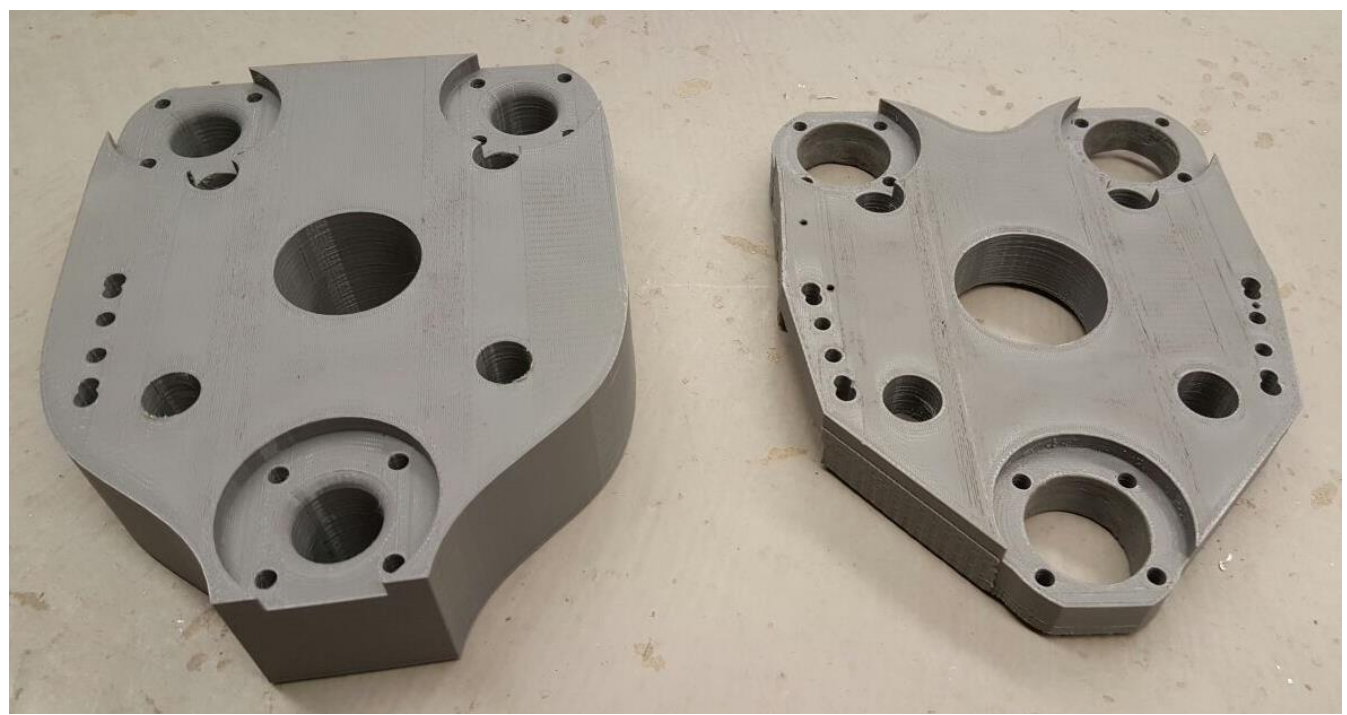

FIGURE 19 - MOTOR MOUNT ITERATIONS, EARLY (LEFT) AND LOW-PROFILE (RIGHT)

\subsubsection{DRILL STEM/BHA}

The drill stem design was partially predetermined because of the prescribed usage of the aluminum drill pipe and drill bit, with the total Bottom Hole Assembly (BHA) not to exceed 13" in length. The BHA material was not specified, and so bearing bronze was chosen because of its weight and machinability. Since the drillpipe was the critical component in terms of strength, maintaining low compression as much as possible was necessary. In regular drill stem designs, thicker walled pipe called a "drill collar" is used immediately after the bit to increase the amount of weight below the regular drill pipe, which is comparatively lightweight. Putting weight below the drill pipe allows for more Weight on Bit (WOB) without compressing the drill pipe to such a large degree, which is important in prolonging the life of the drill stem. An example of the drill pipe is given in Figure 20. 


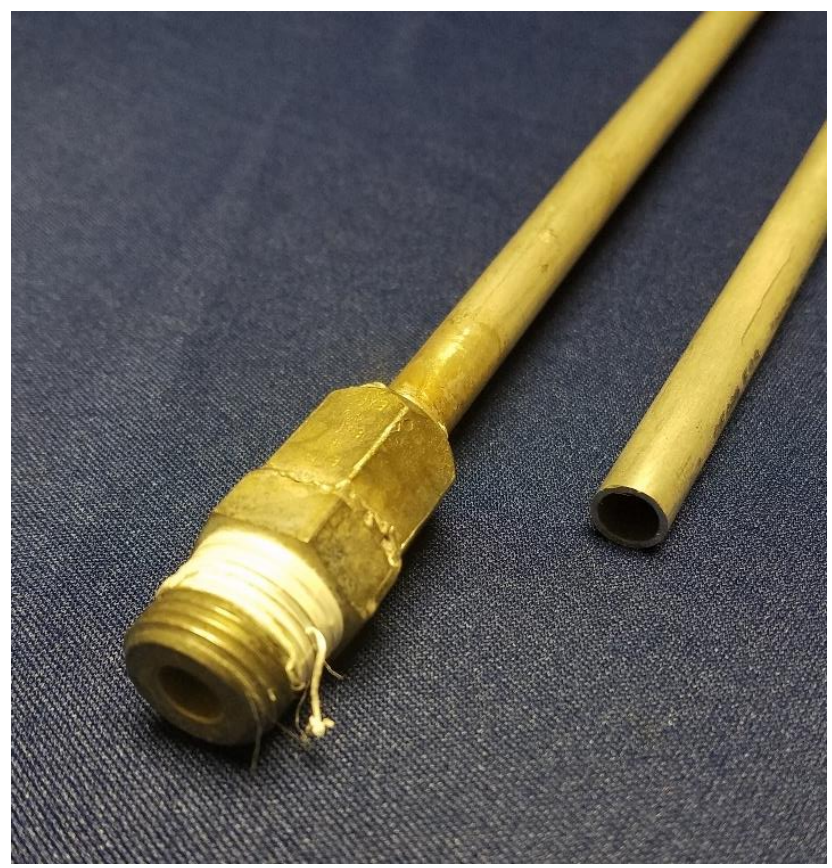

FIGURE 20 - DRILL PIPE, FITTINGS

This concept, along with the desire to utilize stabilizers, led to the decision to use bronze, rather than a heavier metal, in order to machine the BHA with relative ease. The inner diameter of the BHA, once a hole was bored through the center, was $1 / 4$. This was more than adequate for flow inside the BHA but also left enough material that there was an appreciable weight below the drill pipe, approximately $3 \mathrm{lbs}$. In addition to boring a hole through the BHA to allow flow, 4 sections on the $\mathrm{BHA}$ were trimmed down to allow for 3-D printed plastic stabilizers to be fitted. The purpose of the stabilizers was to keep the BHA centered in the bell nipple, and to allow the rig to drill with as little deviation as possible. The stabilizers were designed using plastic, printed in two pieces that could be glued together around the BHA, and plastic was the material of choice so that if the pieces came apart they would not significantly hinder the drilling process. The stabilizers are shown in Figures 21 and 22. 


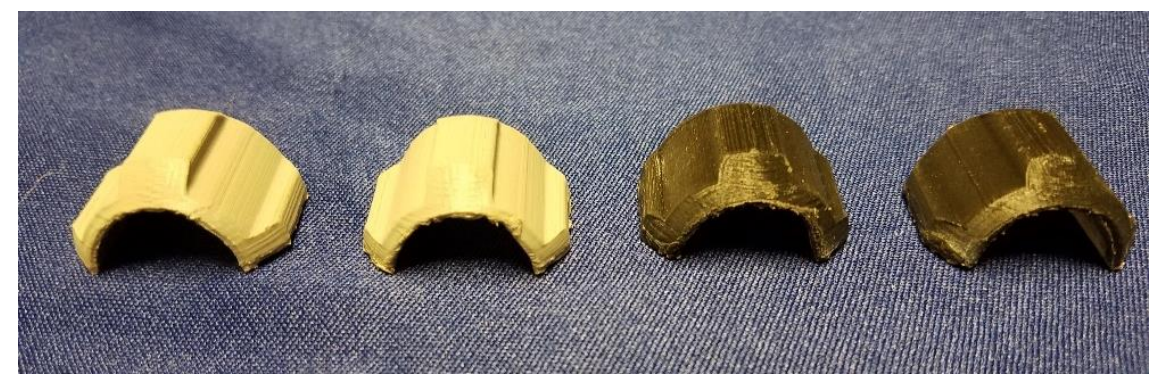

FIGURE 21 - UNATTACHED STABILIZERS

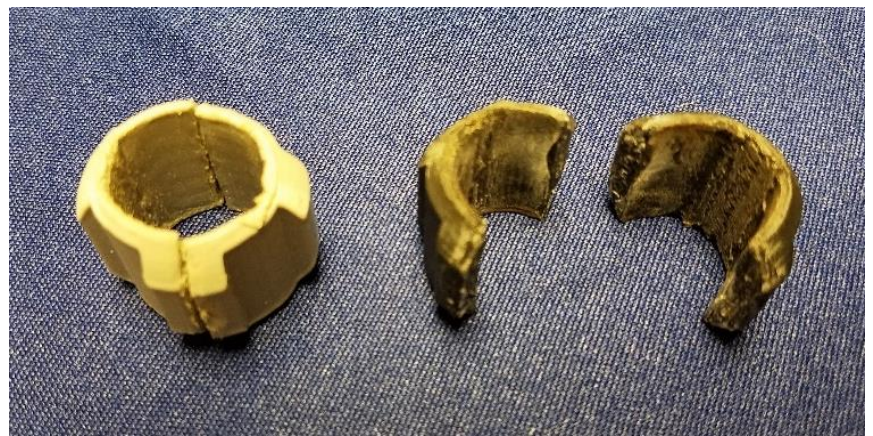

FIGURE 22 - STABILIZER DESIGN

One improvement to stabilizer design would be with the bottommost stabilizer position. The section of BHA that was trimmed down to allow for the stabilizer overlapped the part of the BHA where the interior threading for the bit was located, resulting in the metal being quite thin for approximately $1 / 4$ " of length along the $\mathrm{BHA}$. This was recognized when one of the multiple BHAs that were machined for testing had the end of the BHA break off after drilling through the competition rock sample. However, that BHA had been used previously to drill through several feet of rock without issue, so the overall stress may not have been the only factor in its failure. An example of the final BHA and bit can be seen in Figure 23, and the initial $\mathrm{BHA}$ and bit is shown in Figure 24. Figures 25, 26, and 27 given below show the point of failure, and it was the conclusion that a single method of failure could not be assessed, given the shape and angle of the fracture in the bronze. 


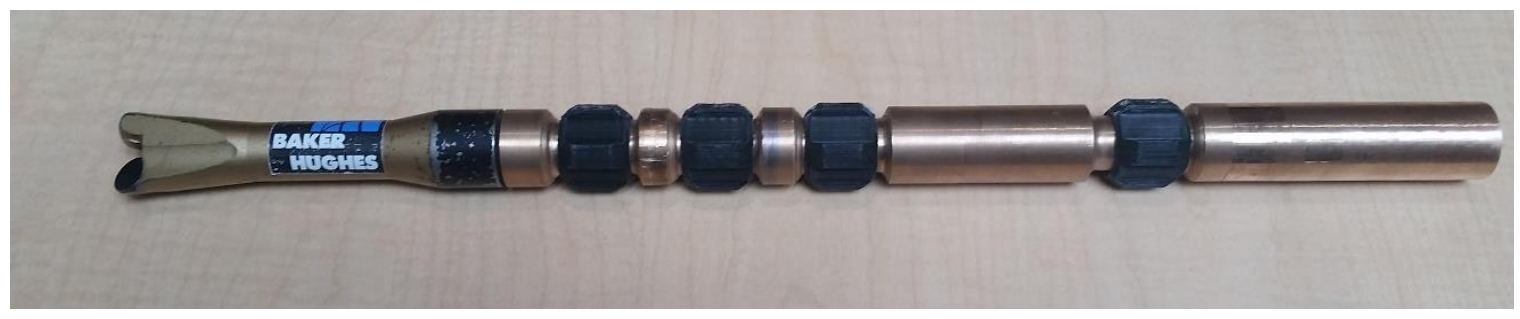

FIGURE 23 - COMPETITION BHA AND BIT

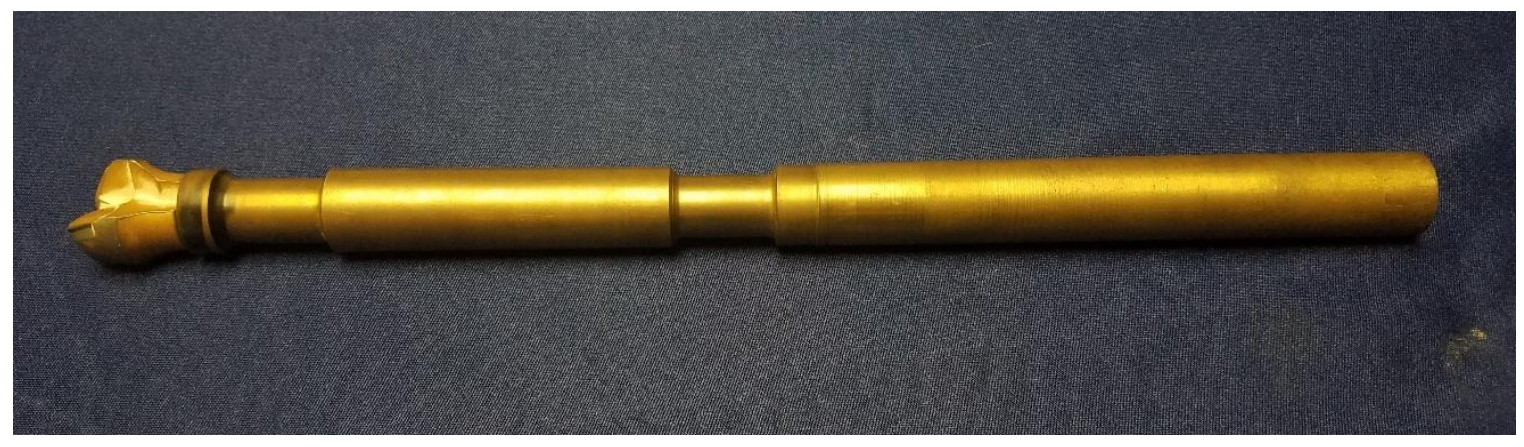

FIGURE 24 - PRE-COMPETITION BHA AND BIT

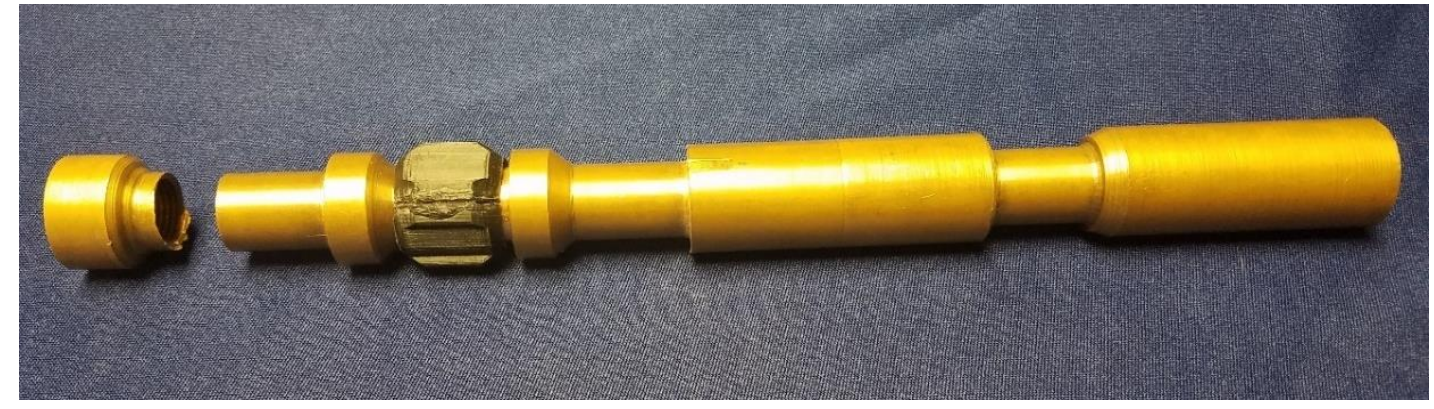

FIGURE 25 - POST COMPETITION FAILED BHA 


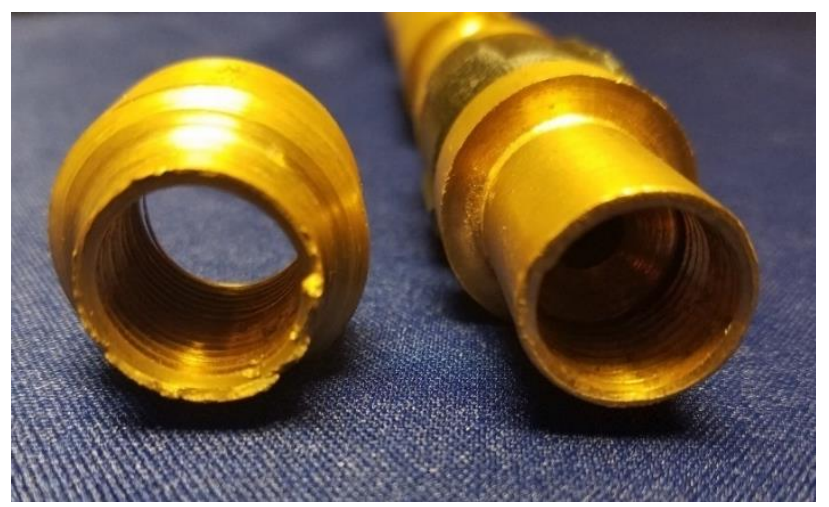

FIGURE 26 - BHA FAILURE

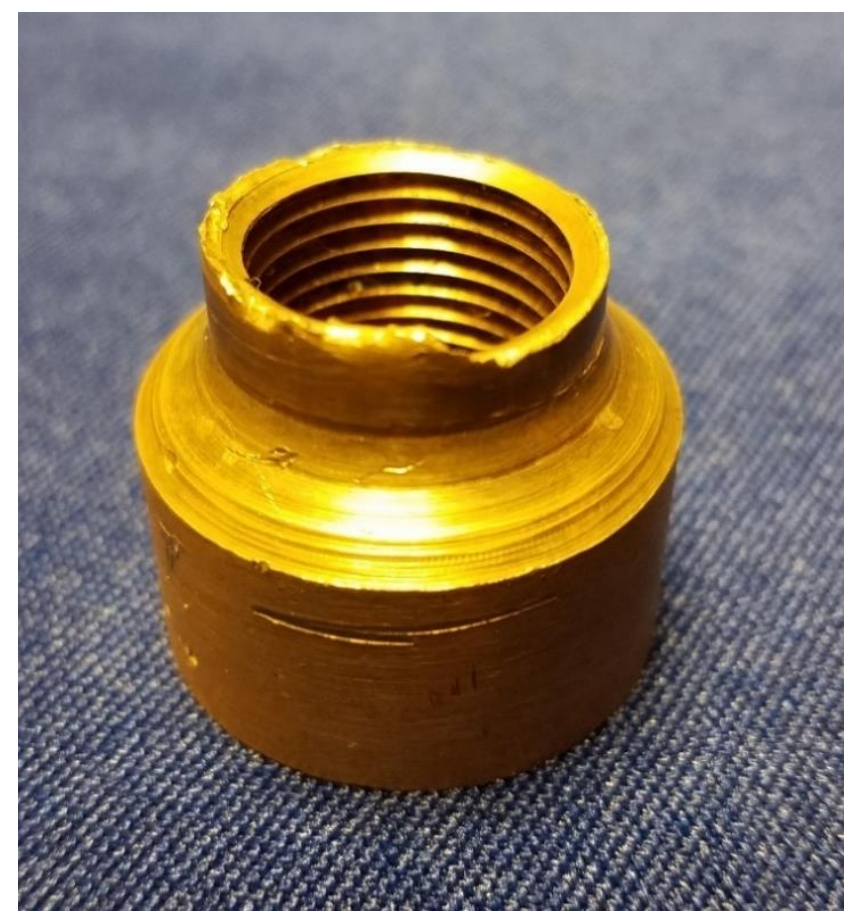

FIGURE 27 - BHA FAILURE CLOSE-UP

\subsection{Mud CiRCULATION SYSTEM}

\subsubsection{PUMP ANALYSIS \& SELECTION}

The need for fluid circulation and filtration is of paramount importance to a drilling operation. While a drilling platform could still drill for a distance without circulating fluid, before long the cuttings would clog the hole and make further progress impossible. Fluid circulation also helps by cooling the drill bit to ensure that it 
remains in working order for as long as possible, maximizing the time the bit can drill, rather than tripping in and out of the well. Thus, designing a fluid circulation system that would enable the rapid and controlled drilling of the rock sample was seen as one of the highest priorities.

With industry drilling rigs, which have to maintain control of pressure along with flow, a Blow Out Preventer (BOP) is typically placed at the surface and has the ability to close the annulus. There are a multitude of different components that can be used along with a BOP, including sensors to measure casing and drill pipe pressure, and valves to allow the operator different options for diverting fluid flow and pressure. A similar system was used, but only had to manage flow as fluid pressure was quickly brought back to atmospheric.

Polymer mud was considered, but it was determined that with the amount of polymer to be mixed, the time and effort required would not outweigh the slight increase to viscosity. Hence, water was used in all hydraulics calculations and for testing purposes. Using the power-law model for the hydraulics design, the following equations (Lyons et al. 2012) provided information on important criteria in designing our circulation system for Jet velocity $\left(\mathrm{V}_{\mathrm{j}}\right)$, Impact force (IF), Cutting Slip Velocity $\left(V_{s}\right)$, and Cutting Transport Ratio (CTR).

$$
\begin{aligned}
& V_{j}=\frac{417.2 * Q(\mathrm{gpm})}{\Sigma\left(\frac{D_{n}^{2}}{32}\right)} \cdot \frac{f t}{\mathrm{sec}} \\
& I F=\frac{V_{j} * \rho * Q}{1930} \cdot l b_{f} \\
& V_{S}=0.45\left(\frac{P V}{M W * D_{p}}\right)\left[\sqrt{\frac{36800 * D_{p}}{\left(\left(\frac{P V}{M W * D_{p}}\right)^{2}\right)} *\left(\frac{\text { DenP }}{M W}-1\right)}-1\right] . f t / \min \\
& \mathrm{CTR}=\frac{\text { Annuluar velocity }- \text { cutting slip velocity }}{\text { Annuluar velocity }} . \%
\end{aligned}
$$

In determining appropriate hydraulics, the cutting transport ratio should be higher than $50 \%$, which it was at all tested flow rates, and the pressure loss across the bit 
should be at or slightly above $50 \%$. With those criteria, it was determined that a flow rate between 1.5 and 3 GPM would suffice to adequately clean the hole (Bilgesu et al. 2017). The resulting calculations at varying flow rates are given in Table 2.

TABLE 2 - MUD HYDRAULICS (BILGESU ET AL. 2017)

\begin{tabular}{|l|l|l|l|l|l|}
\hline $\begin{array}{l}\text { Pump Flow } \\
\text { Rate }(\mathbf{g p m})\end{array}$ & $\begin{array}{l}\text { Pressure losses } \\
(\mathbf{p s i})\end{array}$ & $\begin{array}{l}\text { Annular Velocity } \\
(\mathbf{f t} / \mathbf{s e c})\end{array}$ & $\begin{array}{l}\Delta \mathbf{P}_{\text {bit }} / \mathbf{P}_{\text {pump }} \\
(\%)\end{array}$ & $\begin{array}{l}\text { Impact } \\
\text { Force, (lbf) }\end{array}$ & $\begin{array}{l}\text { Cutting Transport } \\
\text { Ratio CTR, (\%) }\end{array}$ \\
\hline 1.00 & 23 & 1.5 & $48 \%$ & 0.06 & $54 \%$ \\
\hline 2.00 & 29 & 3.1 & $55 \%$ & 0.23 & $77 \%$ \\
\hline 3.00 & 40 & 4.6 & $58 \%$ & 0.51 & $85 \%$ \\
\hline 4.00 & 54 & 6.1 & $60 \%$ & 0.90 & $88 \%$ \\
\hline
\end{tabular}

Since some fluid losses were expected from the rock at the interfaces between layers, it was determined that a closed loop circulating system would be the most beneficial. The other factor in this decision was in trying to automate every process of the drilling. Attempts were made to avoid a system that required a valve to be turned, or for a hose from a water source to limit flow rate. In addition, with the guidelines for disposing of fluid with rock cuttings in it, it would be impractical to have to store and properly dispose of all fluid between each test.

\subsubsection{FILTRATION SYSTEM}

To alleviate these concerns, a closed loop system with a filtration separator was used to recycle the drilling fluid. A 1 HP DC motor drove a gear pump to pull fluid from a reserve tank and pump it into the water swivel and down the drill pipe, where the fluid cleaned the cuttings from the hole after leaving the bit. The fluid then traveled up the annulus of the hole and exit the bell nipple/flow diverter into the wooden separator. The separator was a box approximately 1' wide and 1' deep, by roughly 3' long. There were three wood-framed screens that would be inserted into slots in the box, allowing for different sized mesh screens to be used based on the material being drilled. As the main concern was filtering out particulates large enough to damage the pump, the screen sizes were stepped down from 60 
to 80 to 120 . The screens were made of woven stainless steel, to minimize oxidation, with a 0.0036 " wire diameter and a hole opening size of 0.0047 " in the finest mesh screen. A picture of the pump and pump motor, mounted to the rig, is given in Figure 28.

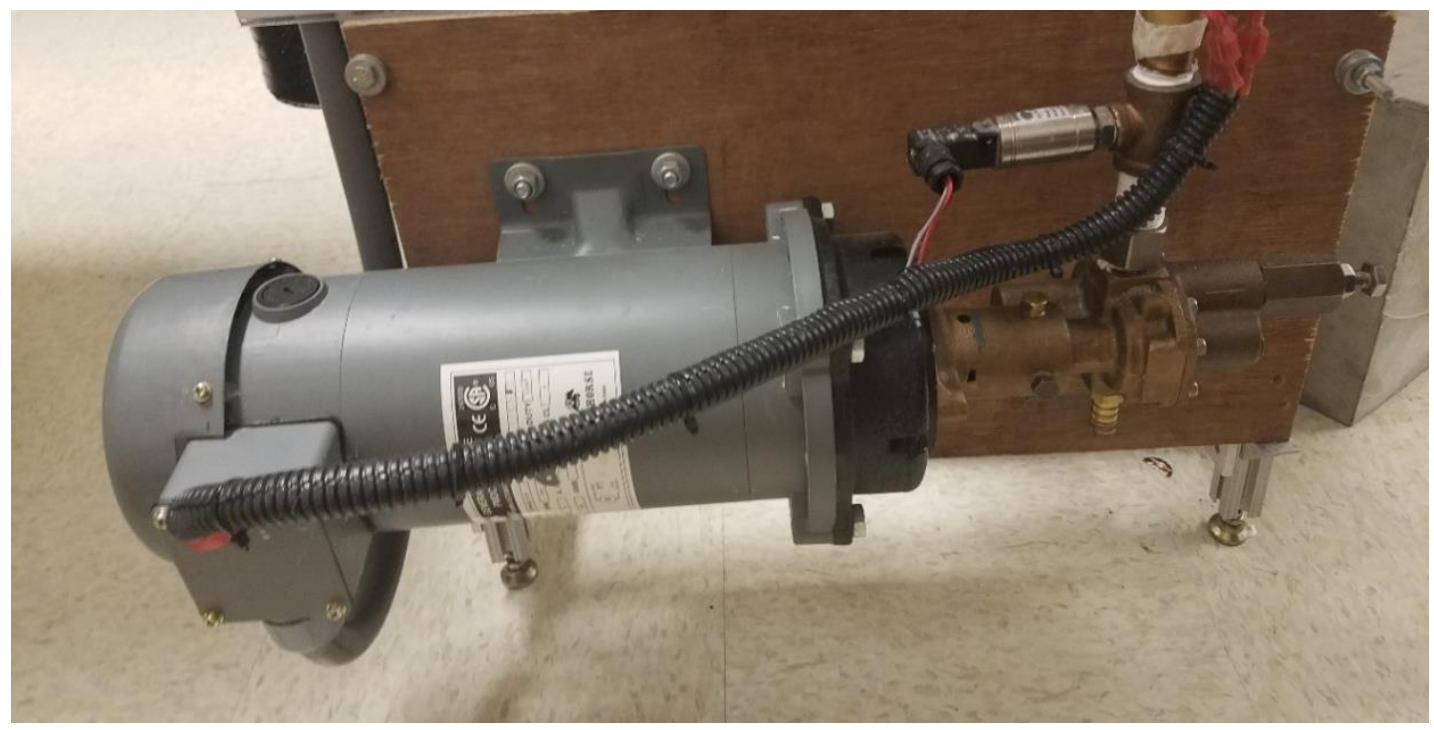

FIGURE 28 - PUMP AND PUMP MOTOR

\subsubsection{RESERVE/StORAGE TANKS}

The reserve and storage tanks were critical to the operation of the circulation system, and thus the rig testing. A plastic container, 10 gallons in capacity, was used as the main tank from which the pump would draw clean fluid. Since the design was meant to be autonomous, the "storage tank" was designed to allow for emergency fluid to be stored and released into the system. The concept of the storage tank was to allow a valve to be turned prior to any testing, and have the system be able to add fluid to the reserve tank any time it dropped below a certain level.

The storage tank had PVC pipe and a ball valve attached and sealed to the side, where the vertical section of PVC would dip below the desired fluid level in the reserve tank. The storage tank was made airtight prior to opening the release valve on the side. Thus, when the valve would open, the only fluid that would flow out initially would be the amount commensurate with the expanded volume of air left 
inside the tank. If the fluid level inside the reserve tank dipped below the PVC opening, air would enter the storage tank and it would release clean fluid until the level went back above the PVC opening. Thus, 35 additional gallons worth of emergency fluid capacity was added to the system. A picture of the fluid filtration and circulation system is given in Figure 29.

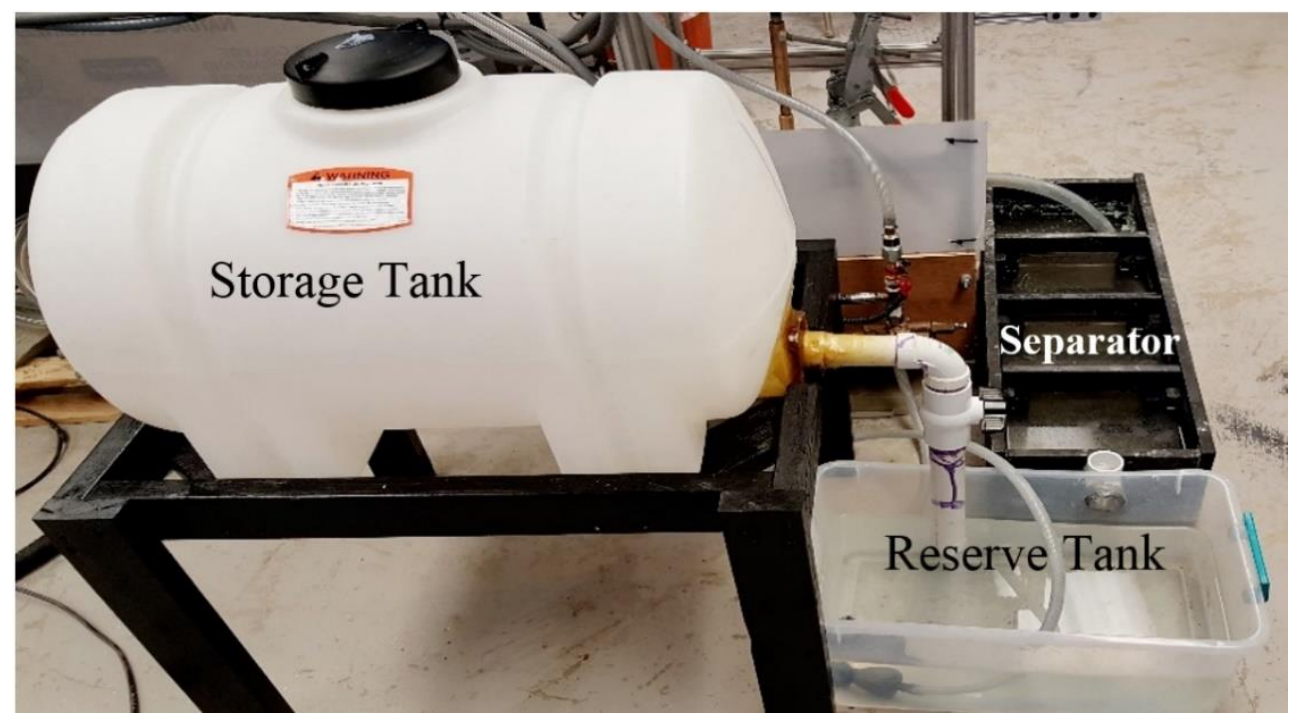

FIGURE 29 - FILTRATION AND CIRCULATION SYSTEM

During the test, the rig progressed through layers of solid sandstone and the fluid that returned up the hole annulus was minimal as most of it traveled between the rock layers and out the bottom of the sample. To mitigate this fluid loss, a plastic berm was placed underneath the rig to catch any lost fluid. A submersible pump could then be used to pump the fluid into the separator to facilitate cleaning and recycle the fluid.

\subsubsection{Bell Nipple ANd Conductor Casing}

Given the desire for a closed loop system, a bell nipple/flow diverter was a necessary component to direct flow out of the annulus and into the separator. This component was the most heavily tested and redesigned because this component was also used as a spacer to clamp the rock sample in place. The two toggle clamps that were mentioned in the Sample Support section of this report utilized 8 " long threaded bolts to push the bell nipple into the rock sample, securing it in 
place and creating a seal that would force the fluid up the bell nipple. Since the bell nipple was responsible for holding the rock in place, it had to be able to withstand a large amount of applied force. Thus, in the design and testing of multiple bell nipples, the fill factor that was used with the 3-D printer, which defines the percentage of open space versus plastic used, was set fairly high to allow for less open space within the form. As with the motor mount, the resulting plastic form had a very high compressive strength-to-weight ratio, and being able to test multiple designs and styles economically allowed precise adjustment of the bell nipple to fit the flow needs exactly. Examples of several of the designs are given in Figures 30 and 31 .

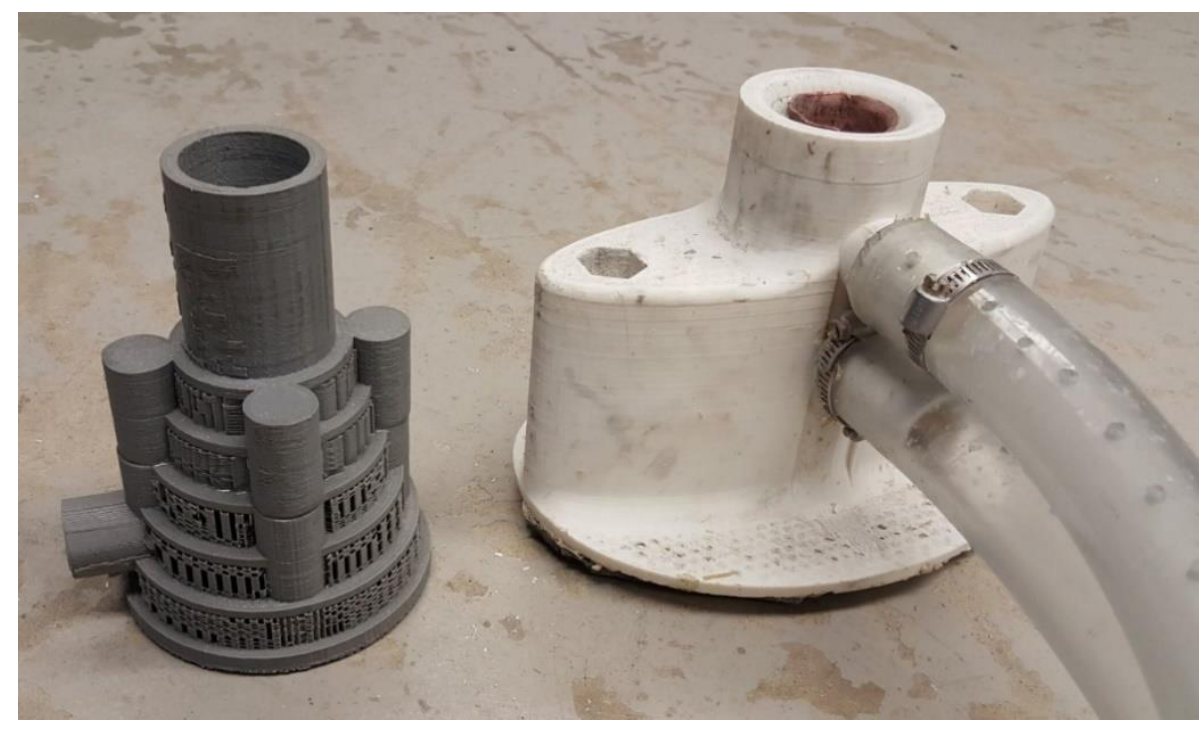

FIGURE 30 -EARLY (LEFT) AND COMPETITION (RIGHT) BELL NIPPLES 


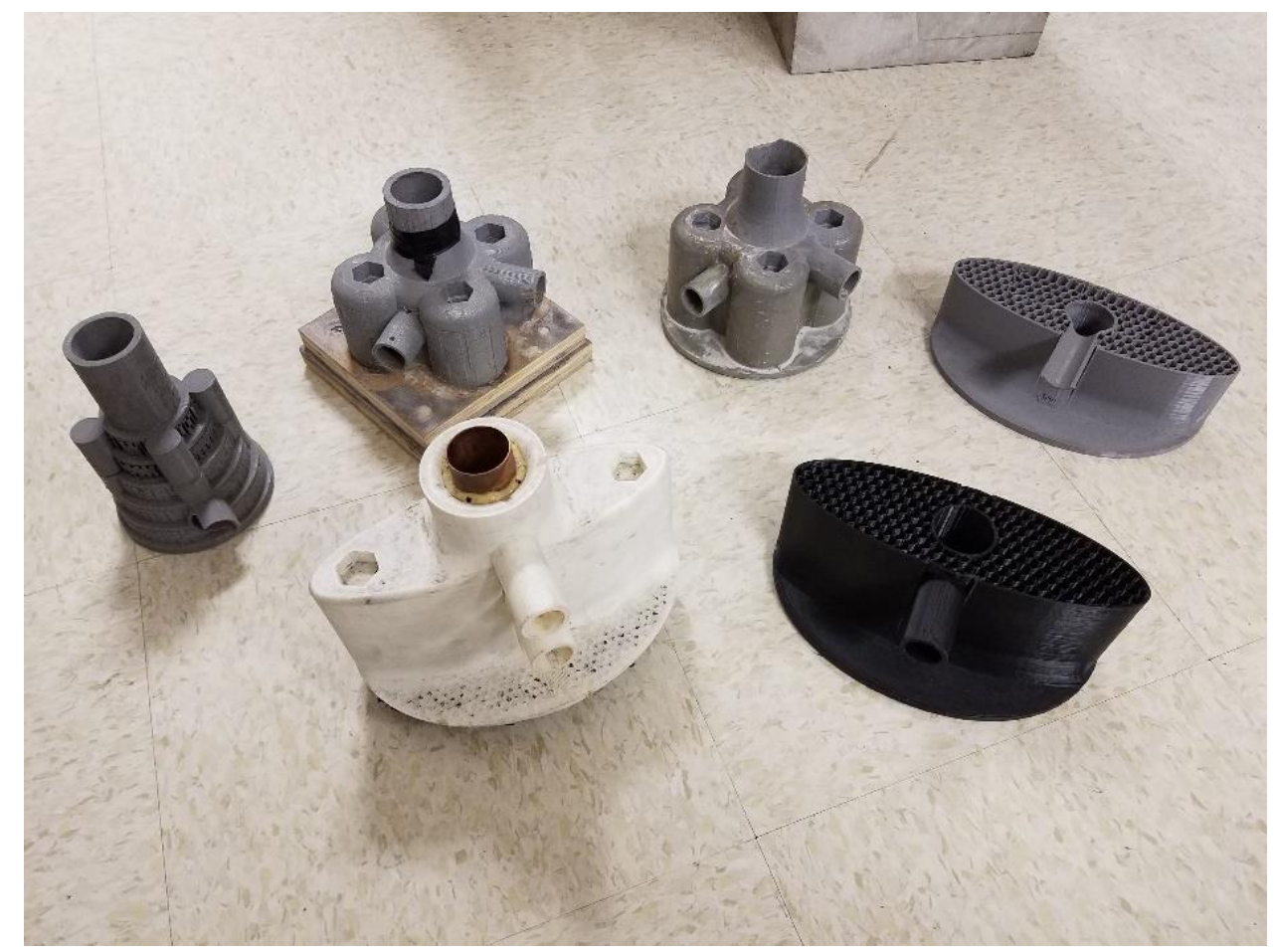

FIGURE 31 - BELL NIPPLE ITERATIONS

It should be noted that any interruption to the 3-D printing process resulted in an unfinished print, with no way to continue with printing to finish the design. This happened multiple times during this research, but the associated loss of time was deemed acceptable for the inexpensive and rapid prototyping of designs. Two of these unfinished bell nipples can be seen as the two rightmost designs in Figure 31 above.

\subsection{AUTOMATION}

\subsubsection{DRILLING VS RIG AUTOMATION}

There is a significant difference between drilling automation and rig automation. Rig automation has already been adopted to varying degrees on most rigs, in the form of positioning control in offshore rigs, to newer automated pipe handling and tripping systems. These systems are comparable to advancements that were made in the manufacturing industry to replace human workers with robotic assembly lines. Using advances in robotics, computer systems, and PLC 
technology, companies can easily and reliably design processes that are capable of limiting or removing human involvement (Thorogood, 2013).

Data collection is of paramount importance in both standard drilling and in any automation scheme. Since drilling involves making changes on the surface without any visual clues as to their effect downhole, monitoring systems are a highly funded and researched division of drilling automation. Some sensors can be placed on the drill stem itself, such as temperature and location of probes, while other data is collected at the surface, such as flow rate and pressure. The collection of downhole data can be achieved using technology termed Measurement While Drilling (MWD). These tools are used more frequently in wells where the inclination angle becomes too steep to push traditional logging tools.

With the emphasis that has been placed in recent years on directional (horizontal) drilling, MWD tools that incorporate gyroscopes and accelerometers, among other sensors, assist the driller in maintaining the well inside a target formation. In addition to horizontal drilling, common practice in the industry has become to drill multiple wells from the same pad to save on cost. This is especially prevalent in areas like the Appalachian Basin where the surface topography makes it difficult to find flat stretches of land large enough to locate a pad. Since companies are now starting several wells with minimal space between them, drilling precisely has become important not just with regards to economics, but to safety as well.

\subsubsection{SENSOR USE}

Since the pilot-scale rig was designed to be fully autonomous, the acquisition and transference of sensor input was a critical component of the rig. Three Arduino boards were used for the control and were directly tied to maintaining sensor information, with the fourth Arduino was used to output data to a computer for recording purposes. While the scope of this study does not include the control algorithm and how the sensor input affected it, a brief summary of the sensors used will follow. 
The most important independent sensor that the rig employed was the strain gauge, which was discussed earlier. The strain gauge sent data to the control box with regard to the weight that was seen at the bit, and the algorithm would send controls to the position control motor to either lift or lower, depending on whether more or less weight was required. Drill stem RPM was determined from the electrically limited drill motor, but the design included a shaft encoder that would verify these speeds. As RPM and WOB were the two biggest factor in the Rate of Penetration (ROP), these inputs were the most critical to the design of a control algorithm that would optimize the drilling rate.

In addition to the RPM and WOB, a linear displacement sensor used a laser and backstop to determine the actual height of the drill motor. This information could be pulled from the position control motor, but in the case of the chain skipping or the system resetting, this input could be used to verify the actual position.

Since one of the specifications was overall power consumption, a wattmeter was attached to the main system surge protector to measure the wattage that all of the components used. This was used in the determination of the total HP all three motors and the controls system used, which was low for the competition.

A strain gauge was also wired to the competition drill pipe to provide information on the strain seen by the thin-walled aluminum, which was the component most likely to fail. However, only one drill pipe was fitted with the strain gauge, so when the drill pipe fittings failed during the testing, that information was no longer recorded with the subsequent pipes. Another important factor in the overall sensor design for the pilot-scale rig, and for industry rigs in general, is redundancy. When an algorithm or an operator is relying on sensor input to make decisions, a bad reading from a sensor can lead to inappropriate decisions being made, whether by an operator or an algorithm. Based on this philosophy, back up sensors were installed for any value deemed critical to the operational algorithm. 


\subsubsection{STATUS LIGHTS}

To provide easily interpreted, highly visible cues as to the operation of the rig, status lights were implemented. The lights consisted of 3 different colored LED strips, 2 of which were used inside the control box and 1 of which was used inside the frame of the rig itself. The three different colors depicted the different operating scenarios, where green lights in the control box indicated that the system was powered up, red lights on the rig frame indicated that the algorithm had been initiated and the rig was drilling, and yellow/orange lights in the control box indicated that the emergency stop button had been depressed. Green lights were meant to convey that approaching the controls box was acceptable, whereas red was designed to give the impression that a reasonable distance should be maintained between the rig and spectators. In aligning these colors with a recognizable color scheme, it was the intention that individuals who were present for the drilling would be aware of what state the rig was in, and whether it was appropriate to approach. An example of each status light can be seen in Figures 32,33 , and 34 .

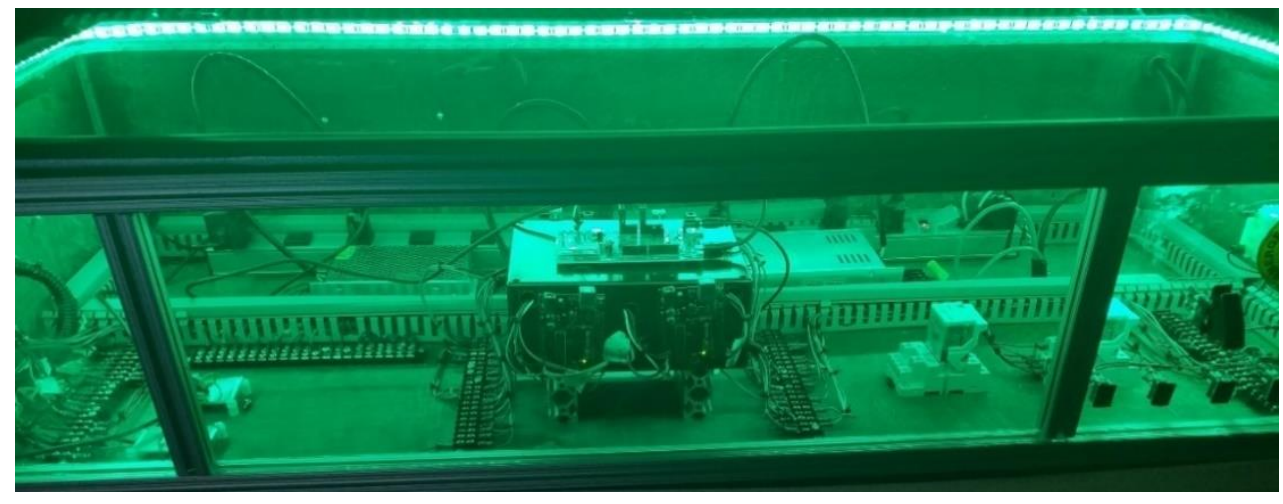

FIGURE 32 - GREEN RIG STATUS LIGHTS 


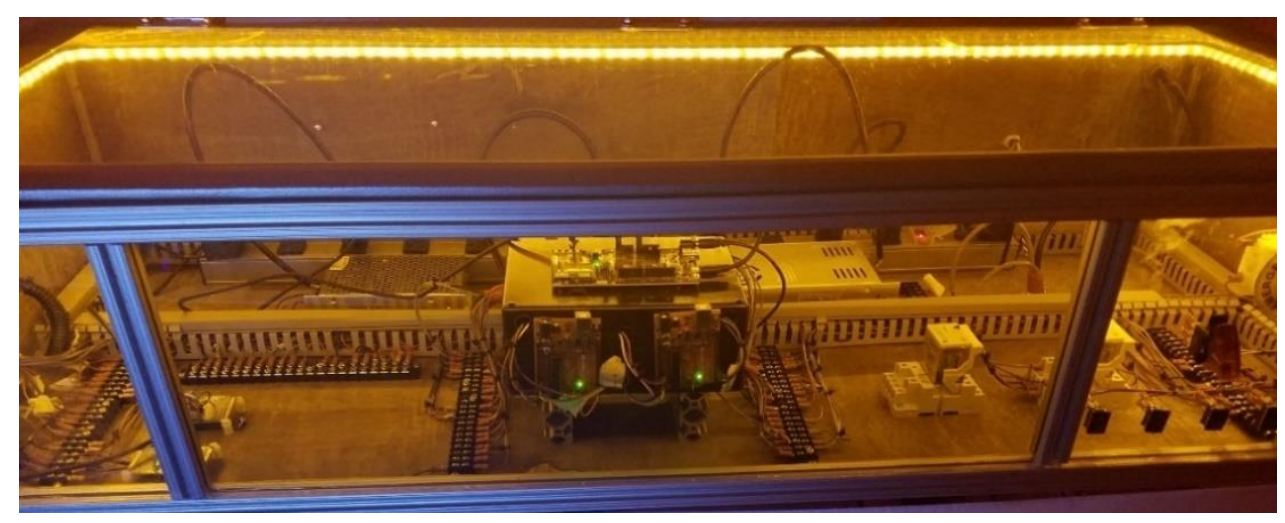

FIGURE 33 - YELLOW RIG STATUS LIGHTS

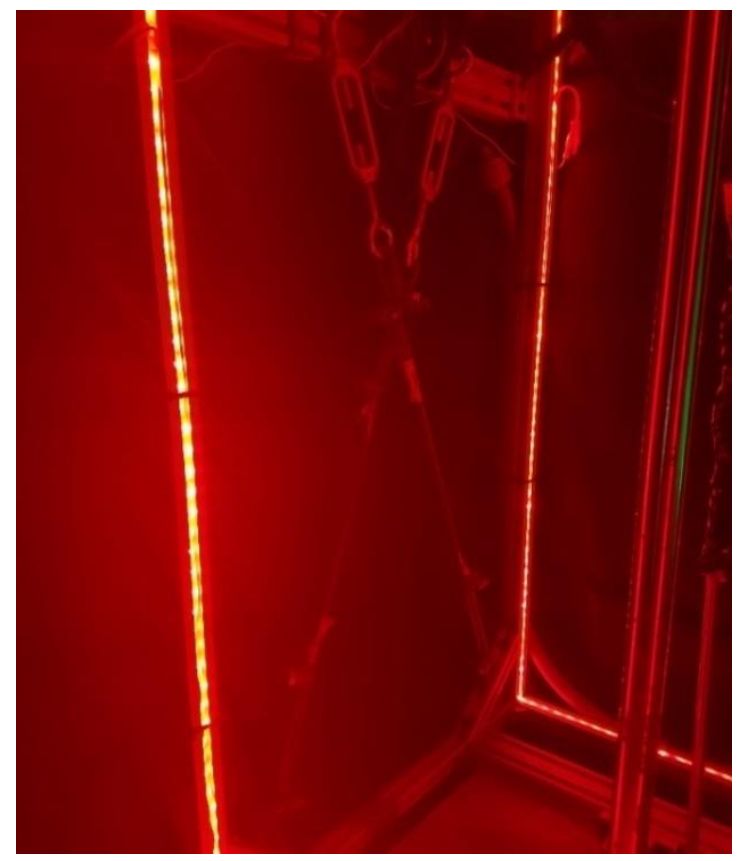

FIGURE 34 - RED RIG STATUS LIGHTS

\subsubsection{TEST RESULTS}

The actual test sample was used as validation for the control algorithm more than for the mechanical design and structure, as the mechanical design had undergone numerous tests to that point. Prior to the testing, dozens of feet of rock were drilled through successfully with no serious mechanical design failures. Approximately 30' worth of 10,000 psi compressive strength sandstone was drilled, along with 4' of 
dolomite, 3' of coal, and over 8' of concrete. Throughout those tests, only one drill pipe, purchased separately for testing purposes, was used.

During the testing of the unit with the supplied drill pipe, fitting and bit, approximately 15 minutes into drilling, the provided pipe fitting failed and the drill stem was unable to spin. The drill pipe was replaced with the other pipe that was provided, but at approximately 24 minutes into drilling, the second drill pipe failed in the same fashion, and it was permitted for the rig to use a drill pipe that had been utilized for testing the composite sample. The total drilling time to finish drilling the 10.5 inches of test sample was 27 minutes. 


\section{CONCLUSIONS}

In this study, a fully automated pilot-scale drilling platform was designed, constructed, and successfully tested. It was determined that rig component analysis, with regard to strength and weight, allows for a rig to be designed with minimum weight to support successful drilling operations. The thin-walled aluminum drill pipe was the obvious component for failure, an analysis was completed to select the drill motor based on the strength of that pipe. Once the analysis showed the lowest power-consuming motor that could provide the desired safety factor, the analysis was extended to show that the other components in the system were indeed less at risk than the drill pipe.

Using structural components that were lightweight and adaptable led to lower construction cost and greater mobility. The design of the rig was adaptable to changes in expected sample size, weight, and drill pipe thickness. A more permanent steel structure would have been less mobile and costlier to adapt to changing circumstances. These conclusions support the use of t-slotted aluminum extrusions in the construction of lab-scale models, where different automation techniques can be tested with various rig configurations.

Several $\mathrm{BHA}$ designs were designed and tested using bearing bronze and plastic non-rotating stabilizers. The BHA design successfully drilled over 40 feet of rock with only one mechanical failure. The stabilizer design mitigated hole deviation even when drilling formations at extreme angles, and gave no indication of disrupting the fluid flow in the annulus of the hole. In addition, the fluid circulation system achieved adequate hole cleaning at an overall low power consumption, and the filtration system allowed the system to be fully automated without any damage to the pump.

The techniques used in this study for drill stem analysis, motor selection, structure selection, and counterweight usage are all applicable to lab-scale models that can be used to test automation practices in the future. The primary outcome from the rig in this study was in the development of an affordable, adaptable, pilot-scale rig 
capable of testing automation algorithms, test bits, drill stem materials, and drilling parameters. The work done in this research may assist companies in designing their own rigs, furthering work than can be done to develop automation at a lower cost. 


\section{RECOMMENDATIONS}

Although the designed rig was successful in drilling multiple samples, there were still several recommendations that could be made to improve upon the design and further the research into rig automation. Designing the corner posts with "quad" rather than "single" aluminum extrusions would add a significant amount of strength to the structure, which may negate the need for the steel cable and turnbuckles. In addition to the added structural strength, the extra mounting rail on each face of a quad would allow for easier attachment of outside components and a more general rig adaptability. Also, the difference in weight between four single posts at 7 ' tall and four quads would only add approximately 25 pounds to the weight of the rig, not including any loss in weight from the steel cable.

Another recommendation for the rig would be to use quick-connect harnesses for the wiring between the control table and the rig, such that the table could be more easily disconnected and removed. In addition to the loss of weight when transporting the rig, making the control table support its own weight would take considerable stress off the supports that were currently used to attach it to the rig. The four corner posts could also be mounted farther apart to allow for larger sample sizes if the table could be supported separately.

The mounting points for the guide rails should also be moved further away from the drill motor to allow for easier access to the sensors attached to the motor mount. The result would be a slightly larger motor mount, adding approximately 1 lb. of material, but significantly easier access to adjust and calibrate the strain gauge and distance sensor.

Drill rig structure analysis has been extensively researched and industry rigs are not limited to a specific thickness of drill pipe, so this research is less applicable to full-scale rigs than pilot-scale in that regard. Drill stem analysis is also commonly studied, so the most important concepts that can be taken from the work done are in the principles that can be applied to designing and utilizing a lab-scale drilling rig to further technology being developed by the industry. 


\section{LIST OF REFERENCES}

Al-Azani, K. H. (30 Nov. 2014). Drilling Rigs Structure: A Comparison between Onshore and Offshore Drilling Rigs with Proposed Future Developments. ResearchGate.

"Aluminum 6061-T6; 6061-T651 Properties." MatWeb: Material Property Data. N.p., n.d. Web. 05 Feb. 2016.

Axelsson, Sven-Åke. (1998) "The Mechanization of Logging Operations in Sweden and Its Effect on Occupational Safety and Health." International Journal of Forest Engineering. N.p., n.d. Web.

Bilgesu, H., Cox, Z., Elshehabi, T.A., Smith, C., Idowu, G. and Florence, F.R. 2017. A Real-Time Interactive Drill-Off Test Utilizing Artificial Intelligence Algorithm for DSATS Drilling Automation University Competition. SPE Western Regional Meeting, Bakersfield, California, USA, 23-27 April. SPE-185730-MS.

De Wardt, J. P. (2012, January 1). Manufacturing Wells: Myth or Magic. Society of Petroleum Engineers. doi:10.2118/151051-MS

Durden, Tyler. "Germany Struggles With Too Much Renewable Energy." ZeroHedge. N.p., 06 Jan. 2013. Web.

Lund, J., C. Cooley, J. Gonzalez, and T. Sexton. "Laboratory Drill Rig for PDC Bearing and Cutter Development." Diamond Tooling Journal (2007): n. pag. Web.

Lyons, W., Carter, T. and Lapeyrousse, N.J. 2012. Formulas and Calculations for Drilling, Production, and Workover - all the Formulas You Need to Solve Drilling and Production Problems, Third Edition: Gulf Professional Publishing, Elsevier.

Macpherson, J. D., de Wardt, J. P., Florence, F., Chapman, C., Zamora, M., Laing, M., \& Iversen, F. (2013, December 1). Drilling-Systems Automation: Current State, Initiatives, and Potential Impact. Society of Petroleum Engineers. doi:10.2118/166263-PA 
Martin, Richard. "Loading up on Wind and Solar Is Causing New Problems for Germany." MIT Technology Review. MIT Technology Review, 21 June 2016. Web.

Mawdsley, John, and Craig Espey. "Renewables vs. Hydrocarbons: The Energy Reality." (2011): n. AltaCorp Capital. Web.

"Modulus of Elasticity or Young's Modulus - and Tensile Modulus for Common Materials." The Engineering ToolBox. N.p., n.d. Web. 16 Feb. 2016.

Talbot, David. "The Great German Energy Experiment." MIT Technology Review. MIT Technology Review, 30 Dec. 2013. Web.

Technology, Electrical. "What Is Industrial Automation, Their Types and Hierarchy of an Industrial Automation System." N.p., 26 Sept. 2015. Web.

Thorogood, J. (2013, March 21). Automation in Drilling: Future Evolution and Lessons From Aviation. Society of Petroleum Engineers. doi:10.2118/151257-PA

Thorogood, J. L., Florence, F., Iversen, F. P., \& Aldred, W. D. (2009, January 1). Drilling Automation: Technologies, Terminology and Parallels With Other Industries. Society of Petroleum Engineers. doi:10.2118/119884-MS

Zamora, M., \& Geehan, T. (2013, March 20). Developing a Drilling Automation Technology Roadmap. Offshore Mediterranean Conference. 